\title{
Development of a Tool to Study Aircraft Trajectory Optimisation in the Presence of Icing Conditions
}

\author{
Ahmed Shinkafi and Craig Lawson \\ School of Engineering, Cranfield University, MK43 0AL, UK \\ a.shinkafi@cranfield.ac.uk
}

\begin{abstract}
With the increasing demand of air travel, the impact on the environment due to aviation has shown a significant increase in recent times. As a result, there is a growing demand for new technologies and flight procedures that will enable aircraft operators to burn less fuel and reduce the adverse effect of aviation on the environment. Conventional approaches to trajectory optimisation do not take the effect of aircraft systems into account. Neglecting these effects may be inadequate, especially when one considers real aircraft operations in real weather scenarios. This research has developed a tool capable of simulating aircraft ice protection performance for trajectory optimisation, which enables the development of a decision making process dependent on weather within the flight management system; thus transforming the conventional IPS (ice protection system) to a more intelligent system. Presently, thermal ice protection methods are the leading ice protection technology on most of the medium and large transport aircraft today. An enhanced aircraft anti-icing (AI) model was developed based on Messinger mass and energy balance method for thermal anti-icing. The tool developed in this work can calculate the total water catch and evaluate power requirement due to icing under a wide range of meteorological conditions. The model was successfully integrated with a trajectory optimisation framework for independent assessment of fuel penalty due to icing and investigation of pollutant emissions reduction through aircraft trajectory optimisation. A case of typical departure from London Airport Heathrow was optimised for fuel burn. The preliminary results show that when operating in known icing condition, including icing parameters in the optimisation loop could give as much as $2 \%$ fuel savings.
\end{abstract}

Keywords: $\quad$ Aircraft icing, anti-icing simulation, icing conditions, trajectory optimisation, IPS design

\section{Introduction}

Aviation is the fastest growing source of global emissions of greenhouse gases from human activity today. It is estimated that more than 300,000 tonnes of $\mathrm{CO}_{2}$ is generated per day from aircraft operations in Europe [1]. As a result, there is a growing demand for new technologies and flight procedures that will enable aircraft operators to burn less fuel and reduce the adverse effect of aviation on the environment.

\subsection{Background of the Research}

The Advisory Council for Aeronautics Research in Europe (ACARE) targets the reduction of $\mathrm{CO}_{2}$ and $\mathrm{NOx}$ emissions by $50 \%$ and $80 \%$ respectively by the year 2020 referenced to aircraft flying in 2000 [2]. The ACARE has identified 
enablers which include next generation systems design as well as more efficient aircraft operation procedures. In the past aircraft trajectory optimisation has been restricted to aircraft dynamics and engine. However, airframe systems consumes about 5-10\% of the total power produced, hence; need to be part of the aircraft optimisation setup to reflect aircraft operations in real weather scenarios. In order to study the effects of airframe systems on aircraft trajectories, it is essential that aircraft systems models for integration with trajectory optimisation frameworks be developed. This is an improvement in the approach to the trajectory optimisation problem since the conventional approach of representing only the aircraft dynamics and the engine fuel model neglects the effects of systems power off-takes. The objective is to optimise trajectories and missions with aircraft systems in operation in order to demonstrate the environmental gains that can be achieved if such optimised flight profiles are flown. This research focuses on the development of a conventional IPS model to be used in trajectory optimisation problems leading to next generation flight procedures.

The leading tools available today for icing analysis include LEWICE [3], TRAJICE2 [4] and ONERA [5]. Others are AID [6], ICECREMO [7], CANICE [8] and FENSAP-ICE3D [9]. These codes are complex and focused heavily on ice growth and a variety of parameters must be computed before commencing the icing analysis. Due to these complexities and the computational penalties, none of these codes can be easily integrated into trajectory optimisation frameworks. Therefore, in order to incorporate icing scenarios in the trajectory optimisation, a simplified icing model which focuses mainly on power requirement had to be developed. Thus, the authors developed, tested and validated the model using Messinger [10] method for aircraft anti-icing. The model which was developed in the MATLAB/Simulink environment would allow independent assessment of aircraft fuel penalties due to icing and assessment of fuel consumption and pollutant emissions reduction through a mission profile optimisation.

\subsection{Aircraft Ice Protection Systems}

Aircraft icing is caused by the freezing of super-cooled water droplets found in clouds when they come into contact with aircraft surfaces. These droplets exist at temperatures below $0^{\circ} \mathrm{C}$ and crystallize once they are in contact with airframe surfaces causing decrease in lift, increase in drag, weight and stall speed [11]. Ice may also accumulate on control surfaces such as flaps and ailerons which could lead to loss of control. Ice accretion could cause damage to engine and external equipment such as probes and antennas. Aircraft IPS is operated either in anti-icing mode or de- 
icing mode. In anti-icing mode, the system is operated continuously or intermittently whereas in de-icing mode, the system is operated only when the accretion passed a pre-determined level.

There are three basic methods of coping with in-flight icing namely: the thermal, mechanical and chemical methods. Sometimes two or more methods are employed to give rise to what is referred to as a hybrid system. Chemical deicers work by applying aircraft de-icing fluids (ADF) such as ethylene glycol on the surfaces to inhibit or delay the reformation of ice. The main dis-advantage of chemical deicers is that they are limited by the amount of chemicals that can be carried on board at a time. Mechanical deicers work on the principle that ice is naturally stiff and brittle, slight distortion therefore fractures it. The shattered ice residues are then swept away by aero forces. This technology has the lowest energy requirement among all in-flight anti/de-icing technologies. They can however be ineffective in exceptional cases and thus limited to small and turbo-prop aircraft. A thermal ice protection system is one in which heat is used either to prevent ice from building up or to remove it once it accumulates over protected surfaces [8].

The type of thermal melting depends on the magnitude of the heat flux delivered to the protected surface. High heat fluxes result in evaporative anti-icing in which the impinging liquid droplets are fully evaporated whereas; wet running involves lower heat fluxes in which the liquid droplets run back as a thin water film on the surface [12]. In an evaporative system, the heat requirements for anti-icing depends strictly on the water catch as a significant amount of energy is required to evaporate all the impinging water droplets. In running wet however, power consumption mainly depends on the ambient temperature. A thermal system can be engine bleed hot air or electrically operated as analysed in [13] and [14]. The major advantage of a thermal system is that the aircraft can be protected in all known or forecast icing conditions [15]. Their major disadvantage is that they impede engine performance due to high power demand [15]. This impediment is compensated for by excess fuel consumption which in turn increases direct operating cost and gas emission [16]. Presently, thermal anti-icing method is the leading ice protection technology on most of the today's medium and large transport aircraft [17].

\subsection{Project Scope}

This work covers the development and validation of an efficient analytical model for estimating the total system burden due to icing. This includes the determination of the boundaries of the parameters that mostly affect the antiicing energy. Knowledge of these boundaries helped in determining the critical cases that need to be considered in the 
second part of this work which is the design of a controllable ice protection system for future generation aircraft, and investigation of energy efficient trajectories. The work includes modelling the wing and engine cowl leading edges and windscreen of a typical medium to large commercial aircraft anti-icing system. A case study of a medium transport aircraft was undertaken to evaluate the performance of the model.

\section{Methodology}

\subsection{Design Standards}

For aircraft to meet airworthiness requirement for flights into icing conditions, it must be equipped with a certified ice protection system. At present, the primary safety regulation is provided by Appendix C of 14 CFR Part 25/CS 25.1419. Appendix C gives two sets of conditions: the Continuous Maximum (CM) for Stratiform clouds, and the Intermittent Maximum (IM) for Cumuliform clouds icing envelopes each as a function of Liquid Water Content (LWC) vs Mean Volumetric Diameter (MVD), and ambient temperature vs pressure altitude. The objective of Appendix C is to provide maximum probable (99\%) icing conditions that could be encountered that the IPS must be able to cope with [18]. The sets of parameters shown in Table 1 applicable to Stratiform and Cumuliform clouds were used in this work.

Table 1 Appendix C Icing Envelope

\begin{tabular}{llllll}
\hline $\begin{array}{l}\text { Cloud } \\
\text { Classification }\end{array}$ & $\begin{array}{l}\text { Horizontal } \\
\text { Extent }(\mathbf{n m})\end{array}$ & $\begin{array}{l}\text { Pressure } \\
\text { Altitude(ft.) }\end{array}$ & $\begin{array}{l}\text { MVD } \\
(\boldsymbol{\mu m})\end{array}$ & $\begin{array}{l}\text { LWC } \\
\left(\mathbf{g} / \mathbf{m}^{3}\right)\end{array}$ & $\begin{array}{l}\text { Ambient } \\
\text { Temperature }\left({ }^{\circ} \mathbf{C}\right)\end{array}$ \\
\hline Stratiform & 17.4 & $0-22,000$ & $15-40$ & $0.04-0.8$ & $-30-0$ \\
Cumuliform & 2.6 & $4,000-22,000$ & $15-50$ & $0.25-2.9$ & $-40-0$ \\
\hline
\end{tabular}

\subsection{Design Point}

Based on the above standards, the design limits of the aircraft IPS are as follows:

- the cloud LWC is above $0.14 \mathrm{~g} / \mathrm{m}^{3}$

- the air or aircraft surface temperature is below $0^{\circ} \mathrm{C}$

- the air temperature is above $-40^{\circ} \mathrm{C}$

- $\quad 15 \mu \mathrm{m} \leq \mathrm{MVD} \leq 50 \mu \mathrm{m}$

However, there is the possibility of encountering Super Cooled Large Droplets (SLD) which refer to super cooled droplets with mean diameter $\geq 50 \mu \mathrm{m}$ including freezing drizzle drops and freezing raindrops. It is regulated that an aircraft must exit such conditions as soon as possible if its ice protection system is certified in accordance with CS/FAR part 25 Appendix C [19]. 


\subsection{Protected Areas}

Large transport aircraft normally utilize engine bleed air for the wing and engine ice protection, and a limited amount of electrical energy for windscreen and probes protection. These areas are those mostly affected by ice formation in flight. Wing icing could lead to complete loss of control and/or insufficient lift to keep the aircraft airborne [11]. In turbofan engines, laminar airflow is required at the face of the fan hence, they are provided with anti-icing system to prevent ice formation. This is because ice formation on engine intakes can cause engine stall or damage to the compressor blades when ingested by the engine. Ice accretion on navigational and communications equipment such as probes and antennas can cause erroneous readings or loss of signals, which could lead to the loss of the aircraft. Therefore, the areas considered for protection against ice formation in the modelling process includes the aircraft wing and engine cowl leading edges, windscreen and probes.

\subsection{Wing and Engine Anti-ice Modelling Process}

The wing and engine anti-icing systems were modelled based on empirical approaches as illustrated in Fig. 1.

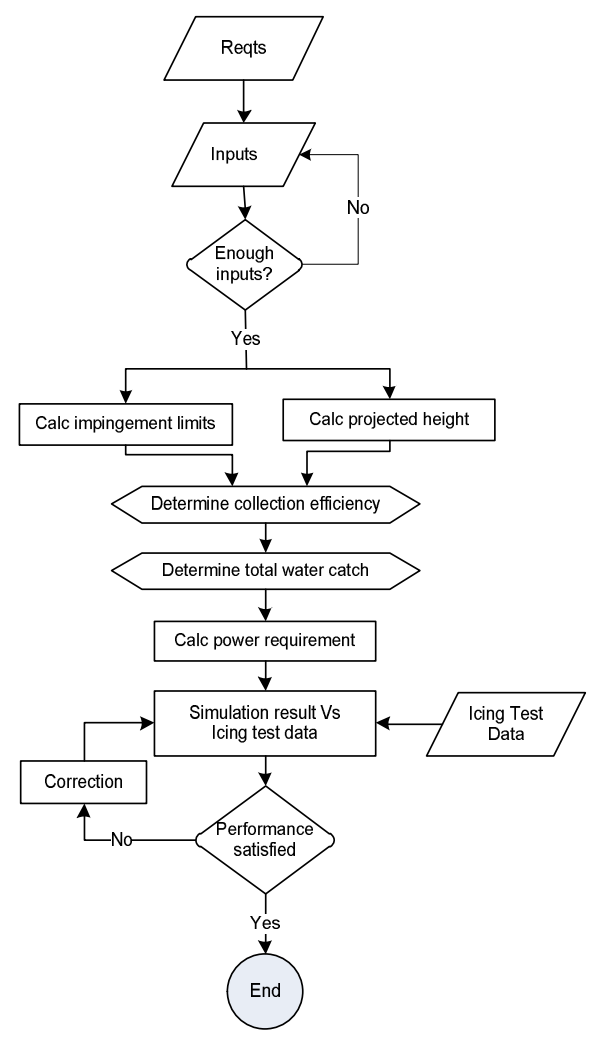

Fig. 1 Modelling Flow Chart

\subsubsection{Baseline Aircraft Description}

The baseline aircraft of this study is a medium transport, twin turbofan engine aircraft with a capacity of between 150 
and 180 passengers, similar to Airbus A320. The aircraft utilizes hot air from the engine for the protection of the three outboard slats (slats 3, 4 and 5) of each wing and two engine nacelles; and limited electrical energy for de-icing the windscreen, probes and waste water drain mast. Although the parameters shown in Table 2 were used in developing the model, the model is reconfigurable for any medium to large fixed wing aircraft.

Table 2. Baseline Aircraft Configuration

\begin{tabular}{ll}
\hline Parameter of Interest & Value \\
\hline Engine pod diameter & $1.7 \mathrm{~m}$ \\
Engines total protected area & $1.12 \mathrm{~m}^{2}$ \\
Flight deck windows area & $2.36 \mathrm{~m}^{2}$ \\
Medial wing Leading edge sweep $\left(\varphi_{L E}\right)$ & $27^{\circ}$ \\
Probes protected area & $0.47 \mathrm{~m}^{2}$ \\
Slat 4 LMAC & $2.5 \mathrm{~m}$ \\
Slat span $(3,4,5)$ & $3.18 \mathrm{~m}$ \\
Wing body setting angle $(\alpha)$ & $4^{\circ}$ \\
Wing gross area & $122.4 \mathrm{~m}^{2}$ \\
Wing Mean Aerodynamic Chord $\left(L_{M A C}\right)$ & $4.19 \mathrm{~m}$ \\
Wing $L_{M A C}$ thickness & $12.50 \%$ \\
Wing Span & $34.1 \mathrm{~m}$ \\
Wing total protected area & $5.7 \mathrm{~m}^{2}$ \\
\hline
\end{tabular}

\subsubsection{Choice of Aerofoil Section}

Information on aerofoil data is an important part of aircraft anti-icing system sizing. It gives an indication of the wing's collection efficiency and total water catch per unit time. The A320 and B737 were the closest aircraft models to the baseline aircraft whose aerofoil information could be used for the analysis. Aerofoil data on A320 was not available whereas B737 aerofoil data is an open source material however; icing parameters data on it were not. Hence, similar aerofoils whose icing data was available such as NACA 23012, NACA 641-212 and NACA 651-212 were compared with B737 aerofoil as shown in Fig. 2.

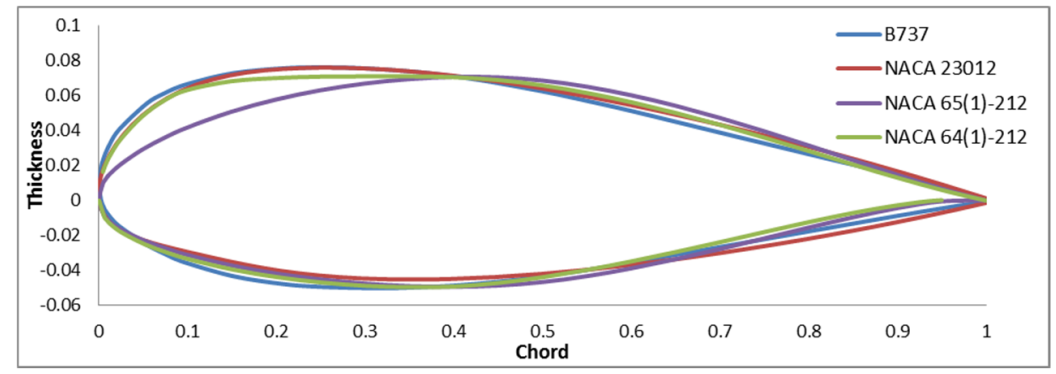

Fig. 2. Comparison of Aerofoil Sections

NACA 23012 and NACA $64_{1-212}$ are quite similar to B737 aerofoil in terms of leading edge radius, camber, 
maximum thickness (12-12.5\% chord) and its position (about 30\% chord). NACA 651-212 has same maximum thickness as B737 but at different position, about $40 \%$ chord to be precise. It also has smaller leading edge radius than the rest aerofoils which means higher impingement efficiency. In addition, because the maximum thickness is positioned at a higher percentage chord, NACA 651-212 will have higher impingement limits. In order to arrive at a conservative anti-icing power estimate, NACA 651-212 aerofoil was chosen for the analysis.

\subsubsection{Impingement Limits Calculations}

In estimating the anti-icing power requirement it is mandatory to establish the limits of water impingement on the surface. To determine how far aft of the leading edge requires protection, the surface upper $\left(\mathrm{S}_{\mathrm{U}}\right)$ and lower limits $\left(\mathrm{S}_{\mathrm{L}}\right)$ were derived as a function of the impingement parameter $\mathrm{K}_{0}$ from a NASA experimental data [20]. Therefore, the corresponding values of the DRR were also read relative to the calculated droplet Reynolds number from [20].

$$
S_{U} / S_{L}=f\left(K_{0}\right)
$$

The inertia factor $K$ which is a precursor to $K_{0}$ was calculated from:

$$
\begin{gathered}
K=\left[\left(\frac{1}{18}\right) \cdot \frac{d_{m e d}^{2} \cdot V_{T A S} \cdot \rho_{\text {water }}}{\mu_{\text {icing }} \cdot L_{M A C}}\right] \\
K_{0}=\text { DRR. } K
\end{gathered}
$$

$D R R=f(R e)$, and

$$
R e_{d}=\frac{d_{m e d} \cdot \rho_{\text {icing }} \cdot V_{T A S}}{\mu_{i c i n g}}
$$

Literature has shown that the $\mathrm{K}_{0}$ factor evaluation method used in this work is correct within $\pm 5 \%$ [21]. Reference [20] presents curves for determining the impingement limits for several aerofoil sections at various angles of attack. The values of $S_{U}$ and $S_{L}$ were evaluated based on the study aircraft data, mission case and NACA $65_{1}-212$ at $4^{\circ} \alpha$. Fig. 3 shows that increase in droplets size is accompanied by increase in the impingement limits for both the upper and lower surfaces. 


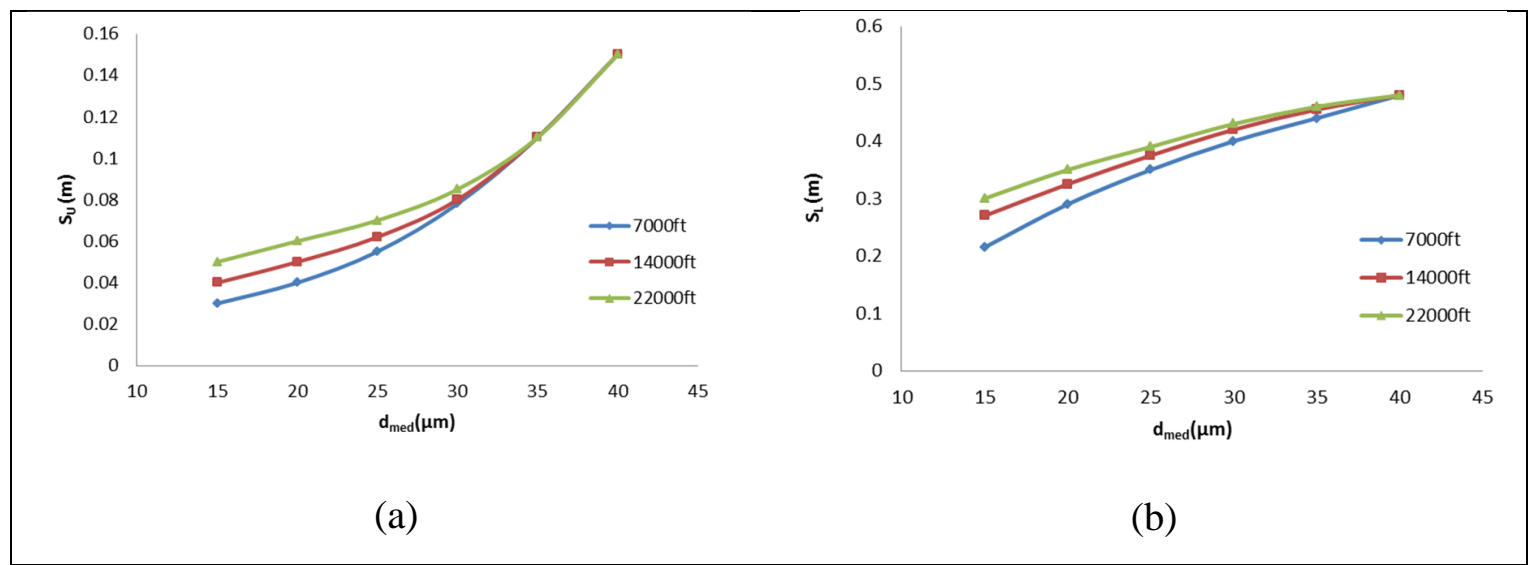

Fig. 3 Impingement Limits as a Function of Droplets Size: (a) Upper Surface - $S_{U}$, (b) Lower Surface - $S_{L}$

\subsubsection{Assumptions}

To simplify the problem, the following assumptions were made:

- Ice melts at a small temperature of $0.01^{\circ} \mathrm{C}$ which indicates that melting and freezing do not occur at the same temperature

- The skin temperature is fixed and known

- Windscreen is assumed to be near vertical and heated electrically

- The probes anti-icing electrical power requirement is assumed to be $10 \%$ that of windscreen

The above assumptions were necessary for ease of simulation. The energy consumption is a function of the heating intensity and the duration of exposure. Therefore, in all simulations, skin temperature to maintain an icing free surface must be defined. Windscreen could be de-iced electrically or use of hot air. However, the baseline aircraft uses electrical energy for windscreen ice protection which informed the use of electrical energy on the windscreen. The number and total probes area exposed to icing is a function of the aircraft type and mission as well as user choice. However, an across the board conservative estimate has been applied in the absence of the total probes area protected in the baseline aircraft.

\subsection{Theoretical Basis}

The basis of the Messinger model [10] is an energy balance which relies on equating the heat lost from the ice and water accretion to the air and the production of latent heat due to ice growth. The mechanisms for losing energy are sensible heating $\left(\dot{q}_{\text {sensib }}\right)$, convective cooling $\left(\dot{q}_{\text {convec }}\right)$, evaporative cooling $\left(\dot{q}_{\text {evap }}\right)$, and those for gaining energy are 
kinetic heating $\left(\dot{q}_{k e}\right)$ and aerodynamic heating $\left(\dot{q}_{a e r o}\right)$. Therefore, thermal balance over the protected surface is performed satisfying the following relationship [10]:

$$
\dot{q}_{a n t i}=\dot{q}_{\text {sensib }}+\dot{q}_{\text {convec }}+\dot{q}_{\text {evap }}-\dot{q}_{k e}-\dot{q}_{a e r o}
$$

Where $\dot{q}_{a n t i}$, is that anti-icing energy which must be supplied to balance the heat losses and gains due to the effects of these terms [22].

\subsubsection{Definition of Energy Terms}

These energy terms are defined as:

\subsubsection{Convective cooling}

The convective cooling is based on Newton's law of cooling given by:

$$
\begin{gathered}
\frac{q}{s_{0}}=h_{0} \Delta t \\
\dot{q}_{\text {local }}=h_{0}\left(T_{s k}-T_{\infty}\right)
\end{gathered}
$$

\subsubsection{Sensible heating}

This is the energy required to raise the temperature of the impinging water to the skin temperature. It is given by

$$
\begin{aligned}
& \dot{q}_{\text {sensib }}=\dot{m} \cdot C_{P_{\text {water }}}\left(T_{\text {sk }}-T_{\infty}\right) \\
& \dot{q}_{\text {sensib }}=\frac{m_{\text {ice }}}{t}\left[\Delta T . C_{P_{\text {ice }}}+L_{f}\right]
\end{aligned}
$$

Sensible heating is a function of specific heat of ice and latent heat of fusion of ice as well as delta T. In this context, $L_{f}$ is not intended to represent sensible heat but rather latent heat of fusion of ice.

\subsubsection{Evaporation energy}

This term varies with the saturated vapour pressure over water at surface equilibrium temperature and is given by [17]:

$$
\dot{q}_{\text {evap }}=0.7 h_{0} L_{e}\left[\frac{R_{h}-e_{\infty}}{P_{\infty}}\right]
$$

\subsubsection{Kinetic energy of incoming water}

The heat gained due to the kinetic energy of the incoming droplets is given by: 


$$
\dot{q}_{k e}=\dot{m}_{\text {local }} \frac{v_{\infty}^{2}}{2}
$$

\subsubsection{Aerodynamic heating}

Aerodynamic heating which is the heat gained due the passage of fluid over a body is given by:

$$
\dot{q}_{\text {aero }}=R_{c} h_{0}\left[\frac{v_{\infty}^{2}}{2 C_{P_{\text {air }}}}\right]
$$

The local heat transfer coefficient $\left(\mathrm{h}_{0}\right)$ can be calculated from:

$$
h_{0}=N u \cdot \frac{k_{0}}{x}
$$

The symbol $k_{0}$ represents the thermal conductivity of air whereas $x$ stands for the leading edge characteristic length, and $R_{c}$ represents the recovery factor.

\subsection{Windscreen/Probes Protection}

Ice builds up on forward facing windscreen panels while flying in icing conditions, posing a risk to the pilot's vision. Hence, windscreens are normally equipped with ice protection systems to allow pilot visibility in case of an icing encounter. Usually, electric current is passed through transparent rows of conductive films located on the inner surface of the outer ply of the windscreen to heat it. In smaller aircraft or where electric power is not available, antifreeze fluids or hot air jets are normally used for windscreen ice protection [23].

This design uses the electrical anti-icing method for windscreen protection. To estimate the electrical power required for anti-icing, the windscreen water catch rate and heat transfer coefficient have to be determined. The total water catch $m_{w s}\left(\mathrm{~kg} / \mathrm{s} . \mathrm{m}^{2}\right)$ of the windscreen projected area was calculated from:

$$
m_{w s}=V \cdot A_{f} \cdot L W C \cdot E_{m}
$$

The windscreen projected area $A_{f}\left(\mathrm{~m}^{2}\right)$ along the line of flight is given by:

$$
A_{f}=2 L_{x} \cdot L_{y}
$$

where $L_{x}$ is the distance from the base to the centre of a nearly vertical windscreen, and $L_{y}$ is the total protected width of the windscreen. The impingement efficiency $E_{m}$ was determined from [23] for semi-infinite triangle. The average 
heat transfer to the centre of the windscreen is given by:

$$
\begin{aligned}
& \bar{h}_{x}=N u_{x} \frac{k}{L_{x}} \\
& N u_{x}=0.0296 \cdot \operatorname{Re}_{x}^{0.8} \cdot \operatorname{Pr}^{0.4}
\end{aligned}
$$

Reference [21] which gives the guidelines for sizing anti-icing system for forward-facing windscreen panels recommends that power input must be adequate to maintain a running wet surface of $1.67 \mathrm{C}$. Therefore, the total heat required for maintaining the windscreen at an equilibrium temperature of $1.67^{\circ} \mathrm{C}$ is given by Eq. 5 whereas the probes and waste water drain mast anti-icing power requirement is assumed to be $10 \%$ that of windscreen.

\subsection{Final Reconfigurable IPS Model}

The final reconfigurable anti-icing model was developed in MATLAB/Simulink ${ }^{\circledR}$ environment as shown in Fig. 5. The model can be updated to include other terms such as radiation and gust effects if required. The model has twelve inputs which could be used to define the study aircraft parameters, atmospheric and mission parameters. These inputs include the speed, Outside Air Temperature (OAT), altitude, LWC, total slat length, wing Leading Edge (LE) sweep angle, and number of engines, engine pod diameter, skin equilibrium temperature droplets size, frontal windscreen length and breadth $\left(L_{x}\right.$ and $\left.L_{y}\right)$ as shown in Fig. 4.

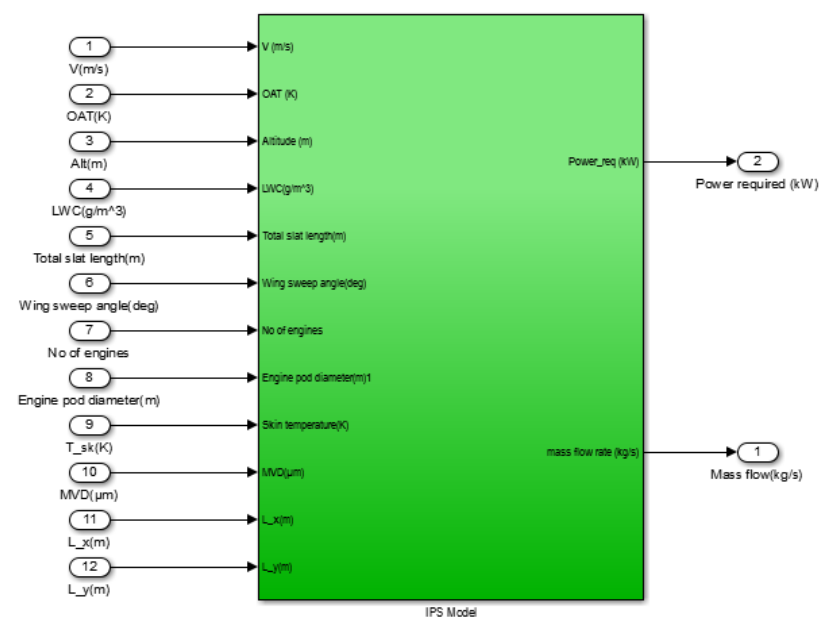

Fig. 4 Reconfigurable Aircraft Anti-icing Model

\section{Parametric Analysis}

The factors affecting aircraft icing are categorised into atmospheric, mission and aircraft related. The atmospheric factors include ambient temperature, clouds LWC, mean droplets size, free stream air density and air speed [23]. The 
major aircraft geometrical parameters are the aerofoil shape/size, wing leading edge sweep and body setting angle. The mission related factors include operating altitude and duration of icing encounter. Overall, these parameters influence the wing total water catch and thus, have significant impact on aircraft icing. As such this section was dedicated to the analysis of the effect of each parameter on the total water catch and anti-icing power requirement. This is necessary in order to establish the critical cases that need consideration in the trajectory optimisation work.

\subsection{Atmospheric parameters}

\subsubsection{Ambient Temperature}

The ambient temperature is by far the most influencing parameter as far as ice accretion is concerned. It affects both the icing severity and the type of ice formed. In the context of aircraft IPS design, icing mostly occurs between 0 to $20^{\circ} \mathrm{C}$ with $-40^{\circ} \mathrm{C}$ being the limit. At $-40^{\circ} \mathrm{C}$ droplets can freeze even without icing nuclei. For a fully evaporative system, it can be noted from Fig. 5 that the required power density for the wing increases with decrease in ambient temperature.

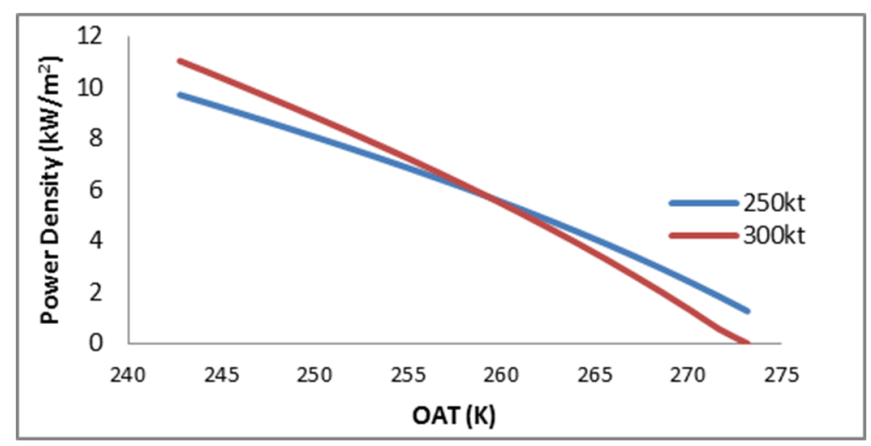

Fig. 5 Effects of Ambient Temperature on the Anti-icing Energy

\subsubsection{Liquid Water Content}

Design atmospheric conditions used in aircraft ice protection certification reflect a relationship between ambient temperature and LWC. LWC is a cubic measurement of a cloud's water content in $\mathrm{g} / \mathrm{m}^{3}$. It gives an indication of how much water is available for icing. Typical values of LWC under Appendix C icing envelope ranges between 0.2 to $1.4 \mathrm{~g} / \mathrm{m}^{3}$. The maximum continuous value of $\mathrm{LWC}$ that may be encountered in stratiform clouds at $0^{\circ} \mathrm{C}$ is $0.8 \mathrm{~g} / \mathrm{m}^{3}$ which reduce to $0.2 \mathrm{~g} / \mathrm{m}^{3}$ at $-30^{\circ} \mathrm{C}$. It could however reach up to $1.7 \mathrm{~g} / \mathrm{m}^{3}$ in cumuliform clouds [18]. A generic icing severity index defined in terms of LWC is contained in Table 3. 
Table 3 Icing Severity Index

\begin{tabular}{lll}
\hline Category & LWC $\left(\mathbf{g} / \mathrm{m}^{3}\right)$ & Accretion \\
\hline Trace & $<0.1$ & $<1 \mathrm{~g} / \mathrm{cm}^{2} / \mathrm{hr}$ \\
Light & 0.11 to 0.6 & $>1 \mathrm{~g} / \mathrm{cm}^{2} / \mathrm{hr}$ \\
Moderate & 0.61 to 1.2 & $>6 \mathrm{~g} / \mathrm{cm}^{2} / \mathrm{hr}$ \\
Severe & $>1.2$ & $>12 \mathrm{~g} / \mathrm{cm}^{2} / \mathrm{hr}$ \\
\hline
\end{tabular}

By definition, trace and light icing do not pose any specific restraints on aircraft behaviour whereas the moderate and severe icing does and thus require mitigating action.

\subsubsection{Droplets size}

The water droplet size given in microns $(\mu \mathrm{m})$ is the measure of mean droplets size often referred to as MVD. Appendix $\mathrm{C}$ icing envelope accounts for conditions below $50 \mu \mathrm{m}$. Aircraft geometry and water droplets size are two parameters affecting collection efficiency and the overall water catch. Though not important like temperature and LWC, droplet size can affect the ice shape as well. This is because droplet size is important in the calculation of the modified inertia parameter $\left(\mathrm{K}_{0}\right)$ which gives a measure of the collection efficiency. The $\mathrm{K}_{0}$ for different droplet sizes was evaluated for the three altitudes that are critical to aircraft icing as represented graphically in Fig. 6.

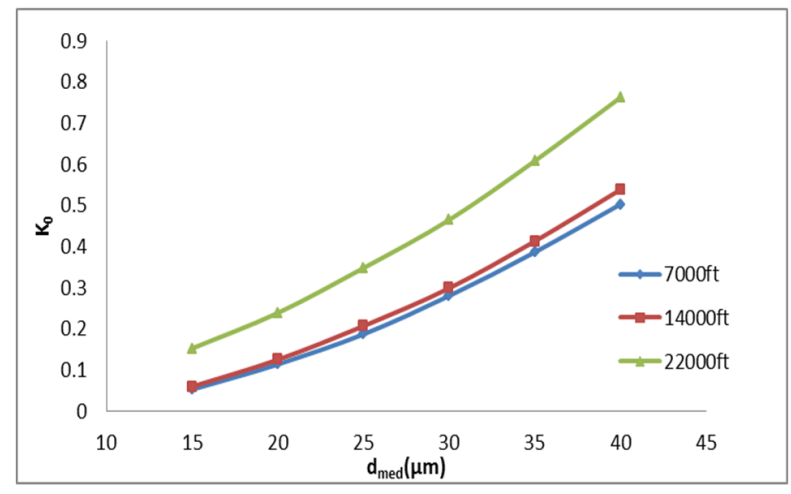

Fig. 6 Modified Droplets Inertia $\left(\mathbf{K}_{0}\right)$

$\mathrm{K}_{0}$ rises with increase in droplet size and altitude. This is because larger droplets are associated with higher inertia and therefore less affected by local aerodynamic forces whereas, droplets with small diameters hence low inertia are likely to flow along the air streamlines and do not impact the surface.

\subsubsection{Relative Humidity}

Relative humidity $(\mathrm{RH})$ helps to represent the saturation of icing potential thus, eliminating areas that do not pose icing hazards. High RH in low temperatures increases icing potential. 


\subsection{Aircraft Parameters}

\subsubsection{Geometry}

The chord size of an aerofoil has a direct link with the projected height it generates. Fig. 7 shows the result of a simple test case involving three conceptualised aerofoils of different chord sizes subjected to same speeds. It can be noted that smaller aerofoils have higher collection efficiency than bigger ones. This is due the fact that the smaller the body the smaller the obstruction it creates against incoming droplets and hence the deviation of the droplets is not sufficient enough for them to avoid the body.

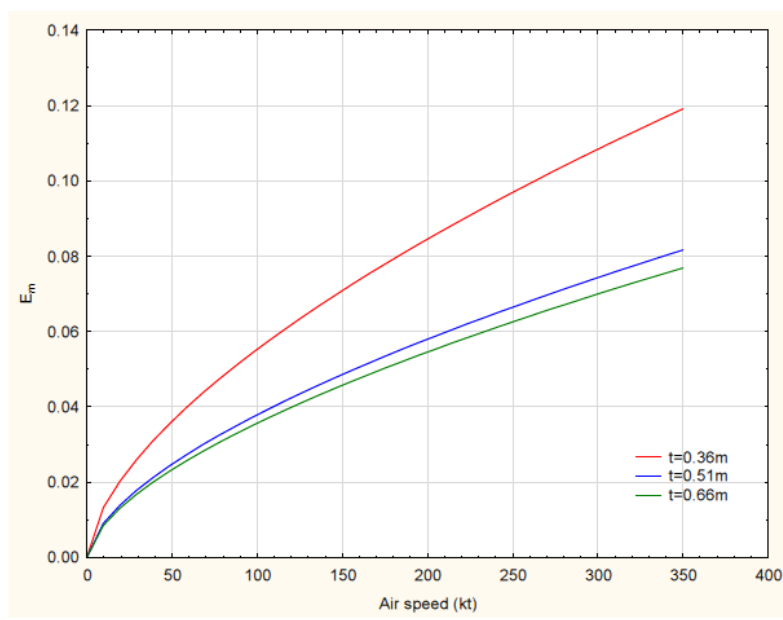

Fig. 7 Air Speed vs Collection Efficiency for Different Aerofoil Sizes

\subsubsection{Angle of Attack}

Aerofoil projected height $\left(h_{\text {proj }}\right)$ is a function of aerofoil geometry and angle of attack $(\alpha)$.

$$
h_{\text {proj }}=f(\alpha)
$$

The experimental data [20] has provided the $(h / C)$ ratio for various aerofoils at different angles of attack. Thus, parameter $h_{\text {proj }}$ was obtained as dimensionless parameter $(h / C)$ from Figures 2 and 3 of the reference experimental data [20]. 


\subsubsection{Collection Efficiency}

Water collection or catch efficiency is the measure of the ability of a body to collects water on its path. The overall collection efficiency $\left(E_{m}\right)$ of a body which is the ratio of the area of impingement to the area through which water passes at a predetermined distance upstream of the aerofoil as illustrated in Fig. 8.

$$
E_{m}=\frac{d y_{t}}{\delta s}
$$

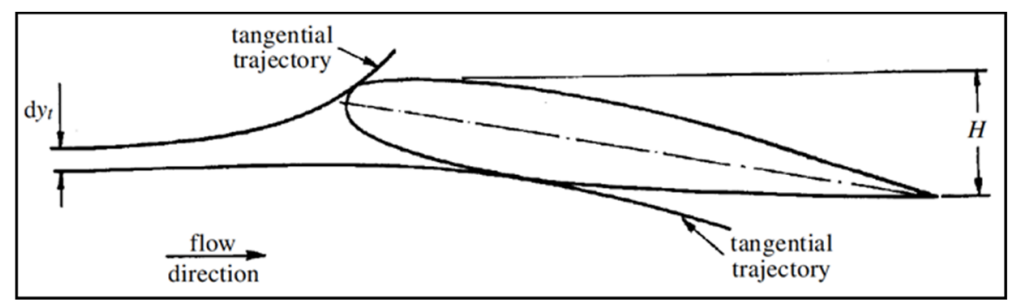

Fig. 8 Definition of Overall Collection Efficiency and Projected Height [11]

The overall collection efficiency enables the determination of the water catch rate of the wing. The $\mathrm{E}_{\mathrm{m}}$ was calculated for different altitudes and droplet sizes as shown in Fig. 9. The result shows that the collection increases with the droplet size and altitude.

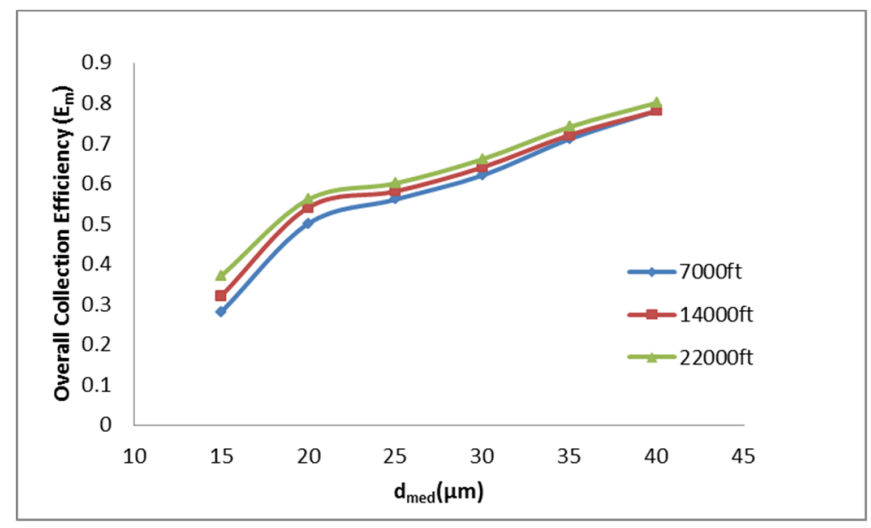

Fig. 9 Overall Collection Efficiency vs Droplets Size

\subsubsection{Total Water Catch}

Water and air are the only recognized substances in an anti-icing system analysis [21]. Water flows on an aerofoil as a thin film, hence its proportions relative to that of the air need to be calculated in anti-icing performance. The difference between the wing surface temperature and the ambient temperature factored by the heat transfer coefficient and amount of water on the wing gives the total heat requirement and related power to generate this heat [24]. The local mass flux of water $\left(\mathrm{g} / \mathrm{s} . \mathrm{m}^{2}\right)$ impinging on the surface is given by: 


$$
\dot{m}_{\text {local }}=\mathrm{V} \cdot L W C \cdot E_{m}
$$

Due to the consideration of the wing leading edge sweep, the airspeed was multiplied by the cosine of the sweep angle.

Therefore

$$
V_{\mathrm{TAS}}=V \cdot \cos \left(\varphi_{L E}\right)
$$

The water catch $(\mathrm{g} / \mathrm{s})$ is the product of the LWC, speed and the droplet collection efficiency for the heated area. Thus, overall water mass flux is given by:

$$
\dot{m}_{w}=L W C \cdot h_{\text {proj }} \cdot V_{\mathrm{TAS}} \cdot L_{M A C} \cdot E_{m}
$$

In the analysis of water catch for different droplet sizes in $\mathrm{CM}$ icing condition for the three altitudes under investigation, the results show that $20 \mu \mathrm{m}$ is the most critical droplet size with the highest water catch and ice thickness as shown in Fig. 10 and Fig. 11 respectively.

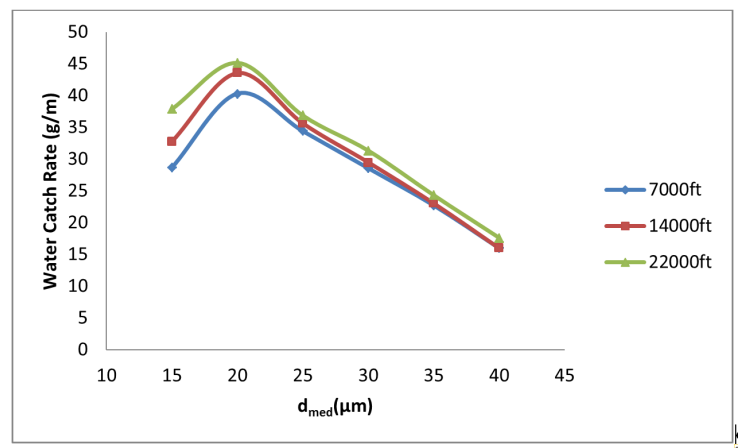

Fig. 10 Total Amount of Water Collected per Unit Span of the Wing for CM Icing Condition

If there is some reason to design for longer or shorter exposure duration, then the LWC originally selected may be reduced or increased by a factor obtained from [18] relating to non-standard operations in Appendix C. However, that was not required in this work as the methodology used in the modelling process yielded an expected result.

During holding in icing condition, an aircraft may be more vulnerable to ice accumulation because of the slower speeds and lower altitudes during this phase of flight. Hence, the general requirement for the design and analysis of inflight ice protection systems recommends a minimum of 45 minutes ice protection capability [18]. Thus, ice 
formation thickness for one meter span in a 45 minutes hold for 7,000 ft (BIG) and 14,000 ft (LYD) using London Heathrow airport standard arrival is shown in Fig. 11.

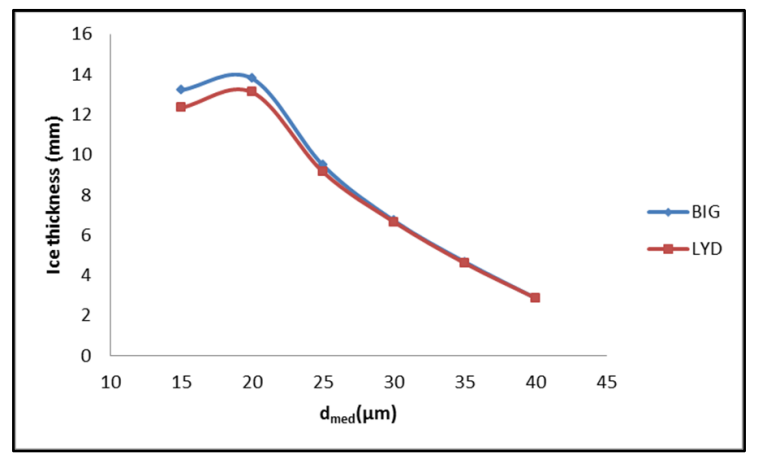

Fig. 11 Ice Formation Thickness for I Meter Span, Hold (45mins)

\subsection{Mission Parameters}

\subsubsection{Altitude and Air Speed}

The ambient temperature normally reduces with altitude, hence icing potentials increase with altitude as well. However, Fig. 12 shows that anti-icing power demand is higher at low altitudes due the effects of density which is higher at lower altitudes and water rich clouds.

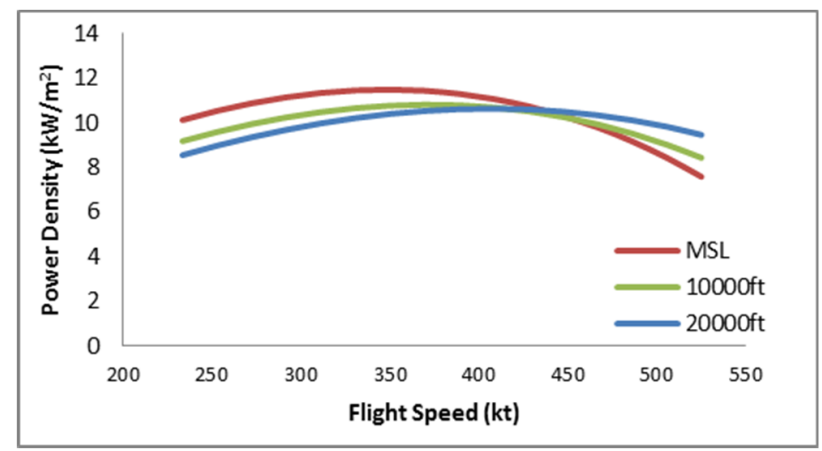

Fig. 12 Power Density as a Function of Flight Speed and Altitude

The airspeed increases the volume of intercepted water per unit time and, aerodynamic and kinetic heating effects. It can be noted from Fig. 12 that power requirement increases with airspeed until about $430 \mathrm{kt}$ when the aerodynamic and kinetic heating start to take effect. This means that as speed increases, the temperature range at which ice accretes starts to shift towards low temperature region. 


\subsubsection{Duration of icing Encounter}

The longer the aircraft spends in an icing encounter, the larger the ice accretion. Duration $\left(t_{\text {icing }}\right)$ of icing encounter can be estimated by dividing the standard horizontal extent ( $S_{\text {horizontal }}$ ) for the continuous and intermittent maximum conditions by the aircraft ground speed $\left(V_{T A S}\right)$ [16]. Since, the total water catch is a function of the time spent in icing condition; this means that it is also speed dependent. Therefore, multiplying the exposure period with the calculated rate of water catch gives the total amount of water collected per unit length of the wing span $(\mathrm{g} / \mathrm{m})$.

$$
\begin{aligned}
& t_{\text {icing }}=\frac{S_{\text {horizontal }}}{V_{T A S}} \\
& m_{\text {water }_{\text {total }}}=\dot{m}_{w} \cdot t_{\text {icing }}
\end{aligned}
$$

\section{IPS Model Application Case Study}

To test the functionality of the tool developed in this work, an academic test case was developed using the baseline study aircraft parameters specified in Table 4. A snap shot of a simpler version of the model developed to run case study is shown in Fig. 13.

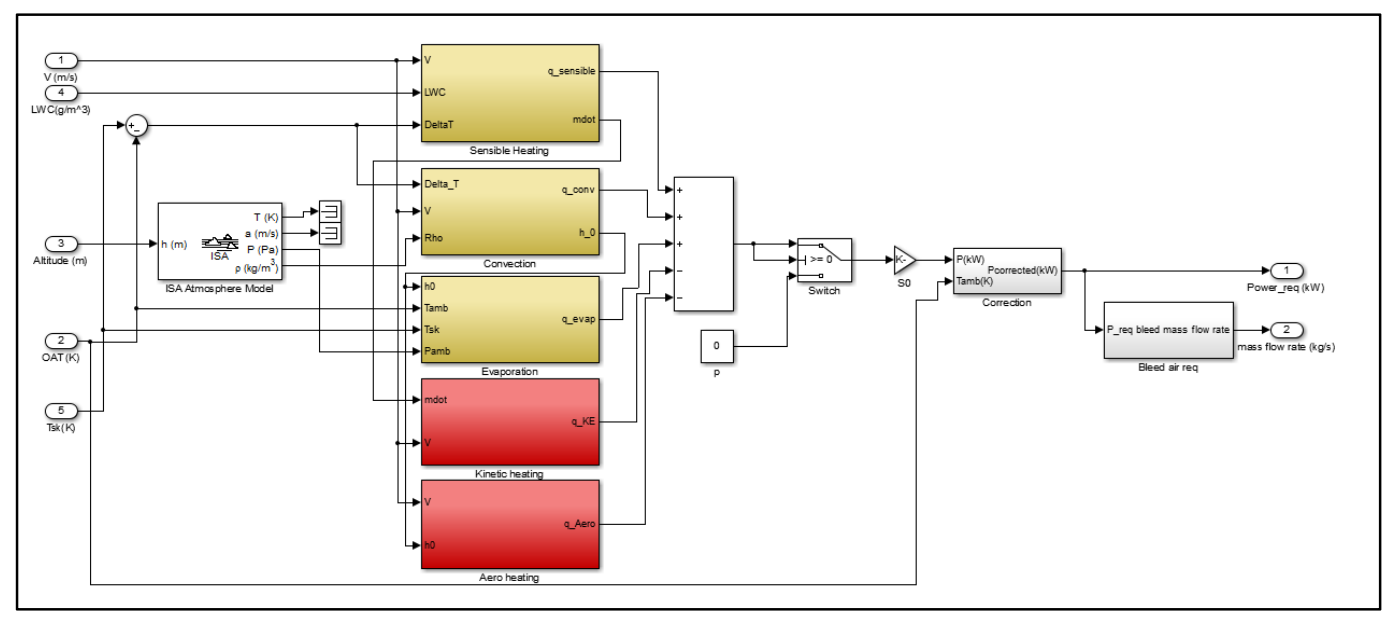

Fig. 13 A Representative Anti-icing Model for the Baseline Aircraft

To simplify the calculation for the study case, the parameters that are particular to the test case were defined as constants within the model. The values of inputs and inputs used are listed in Table 4. 
Table 4 Summary of Parameters and Values Used for Study Case

\begin{tabular}{lcl}
\hline & Inputs & \\
\hline Parameter & Values & Units \\
\hline Altitude $(h)$ & User define & $\mathrm{ft}$ \\
Ambient temperature $\left(T_{\infty}\right)$ & User define & ${ }^{\circ} \mathrm{C}$ \\
Surface heat transfer area $\left(S_{0}\right)$ & User define & $\mathrm{m}^{2}$ \\
Flight speed $\left(V_{T A S}\right)$ & User define & $\mathrm{kt}$ \\
Clouds liquid water content $(L W C)$ & User define & $\mathrm{g} / \mathrm{m}^{3}$ \\
\hline & Internal constants & \\
\hline Mean aerodynamic chord $\left(L_{M A C}\right)$ & 2.2 & $\mathrm{~m}$ \\
Slat length $\left(y_{S L A T}\right)$ & 3.14 & $\mathrm{~m}$ \\
Leading edge sweep $\left(\varphi_{L E}\right)$ & 27.5 & $\circ$ \\
Skin temperature $\left(T_{s k}\right)$ & 5 & ${ }^{\circ} \mathrm{C}$ \\
MVD $\left(d_{\text {med }}\right)$ & 20 & $\mu \mathrm{m}$ \\
Pressure $(\mathrm{P})$ & $f(\mathrm{~h})$ & $\mathrm{hPa}$ \\
Saturation pressure $(e)$ & $f(T)$ & $\mathrm{hPa}$ \\
Relative humidity $(R h)$ & 100 & $\%$ \\
Specific heat of air $\left(C_{P_{\text {air }}}\right)$ & 1005 & $\mathrm{~J} / \mathrm{kg} . \mathrm{K}$ \\
Specific heat of water $\left(C_{P_{\text {water }}}\right)$ & @ $0^{\circ} \mathrm{C}$ & $\mathrm{J} / \mathrm{kg} . \mathrm{K}$ \\
Specific density of water $\left(\rho_{\text {water }}\right)$ & 1000 & $\mathrm{Kg} / \mathrm{m}^{3}$ \\
Latent heat for water evaporation $\left(L_{e}\right)$ & 2257 & $\mathrm{~kJ} / \mathrm{kg}$ \\
Latent heat of fusion $\left(L_{f}\right)$ of $i c e$ & 332.5 & $\mathrm{~kJ} / \mathrm{kg}$ \\
Air density $(\rho)$ & $f(h)$ & $\mathrm{kg} / \mathrm{m}^{3}$ \\
Absolute viscosity of air $(\mu)$ & $1.5636 x 10^{-5}$ & $\mathrm{~kg} / \mathrm{s.m}$ \\
Thermal conductivity of air $\left(k_{0}\right)$ & 0.0228 & $\mathrm{~W} / \mathrm{m} . \mathrm{K}$ \\
\hline & Outputs & $\mathrm{kW}$ \\
\hline Heat flux $\left(\dot{q}_{\text {anti }}\right)$ & Result & $\mathrm{kg} / \mathrm{s}$ \\
Bleed mass flow rate $\left(\dot{m}_{\text {bleed }}\right)$ & &
\end{tabular}

\subsection{Results and Discussions}

Thermal IPS' are designed for maximum energy requirements which usually occur at between $250 \mathrm{kt}$ and $350 \mathrm{kt} V_{T A S}$. At higher velocities kinetic heating outweighs convective losses and thus eliminates the need for anti-icing. It is known that most icing occurs at temperatures between 0 and $-20^{\circ} \mathrm{C}$ and more than $50 \%$ of that occurs between -8 and $-12^{\circ} \mathrm{C}$ [25]. But this range does not indicate the most critical design point. The critical design point for the IPS is when the power requirement is highest from an engine perspective the engine should be able to supply bleed air to satisfy this requirement. At each point the permissible bleed extraction should be adequate to supply the combine airflow requirement for both ECS and IPS. The engine manufactures would consider the secondary power bleed requirement throughout a vast flight envelope when deciding the offtakes limit. Hence, the whole Appendix C envelope was covered using 24 cases (see Table 5) to determine the most critical design point.

Table 5. Simulated Icing Conditions

\begin{tabular}{lllllll}
\hline & \multicolumn{3}{l}{ CM Conditions } & \multicolumn{5}{l}{ IM Conditions } \\
\hline Case & $\begin{array}{l}\text { OAT } \\
\left({ }^{\circ} \mathbf{C}\right)\end{array}$ & $\begin{array}{l}\text { LWC } \\
\left(\mathbf{g} / \mathbf{m}^{\mathbf{3}}\right)\end{array}$ & $\begin{array}{l}\text { MVD } \\
(\mathbf{m} \boldsymbol{\mu})\end{array}$ & $\begin{array}{l}\text { OAT } \\
\left({ }^{\circ} \mathbf{C}\right)\end{array}$ & $\begin{array}{l}\text { LWC } \\
\left(\mathbf{g} / \mathbf{m}^{\mathbf{3}}\right)\end{array}$ & $\begin{array}{l}\text { MVD } \\
(\mathbf{m} \boldsymbol{\mu})\end{array}$ \\
\hline 1. & 0 & 0.8 & 15 & 0 & 2.8 & 15
\end{tabular}




\begin{tabular}{lllllll}
2. & -10 & 0.6 & 15 & -20 & 1.9 & 15 \\
3. & -20 & 0.3 & 15 & -30 & 1.14 & 15 \\
4. & -30 & 0.2 & 15 & -40 & 0.25 & 15 \\
5. & 0 & 0.63 & 20 & 0 & 2.6 & 20 \\
6. & -10 & 0.43 & 20 & -30 & 0.95 & 20 \\
7. & -20 & 0.23 & 20 & -40 & 0.23 & 20 \\
8. & -30 & 0.15 & 20 & 0 & 1.75 & 20 \\
9. & 0 & 0.48 & 25 & -20 & 1.18 & 25 \\
10. & -10 & 0.3 & 25 & -40 & 0.14 & 25 \\
11. & -20 & 0.16 & 25 & 0 & 1.3 & 25 \\
12. & -30 & 0.08 & 25 & -10 & 1 & 25 \\
13. & 0 & 0.365 & 30 & -30 & 0.45 & 30 \\
14. & -10 & 0.23 & 30 & -40 & 0.12 & 30 \\
15. & -20 & 0.13 & 30 & 0 & 0.95 & 35 \\
16. & -30 & 0.06 & 30 & -20 & 0.57 & 35 \\
17. & 0 & 0.26 & 35 & -40 & 0.1 & 35 \\
18. & -10 & 0.16 & 35 & 0 & 0.75 & 40 \\
19. & -20 & 0.07 & 35 & -10 & 0.55 & 40 \\
20. & -30 & 0.05 & 35 & -40 & 0.1 & 40 \\
21. & 0 & 0.165 & 40 & 0 & 0.6 & 45 \\
22. & -10 & 0.1 & 40 & -40 & 0.1 & 45 \\
23. & -20 & 0.065 & 40 & 0 & 0.38 & 50 \\
24. & -30 & 0.05 & 40 & -40 & 0.1 & 40 \\
\hline
\end{tabular}

\subsubsection{Continuous Maximum Icing Condition}

Fig. 14 shows the response of the power density to different temperature bands $\left(0^{\circ} \mathrm{C},-10^{\circ} \mathrm{C},-20^{\circ} \mathrm{C}\right.$ and $\left.-30^{\circ} \mathrm{C}\right)$ at different speed settings.

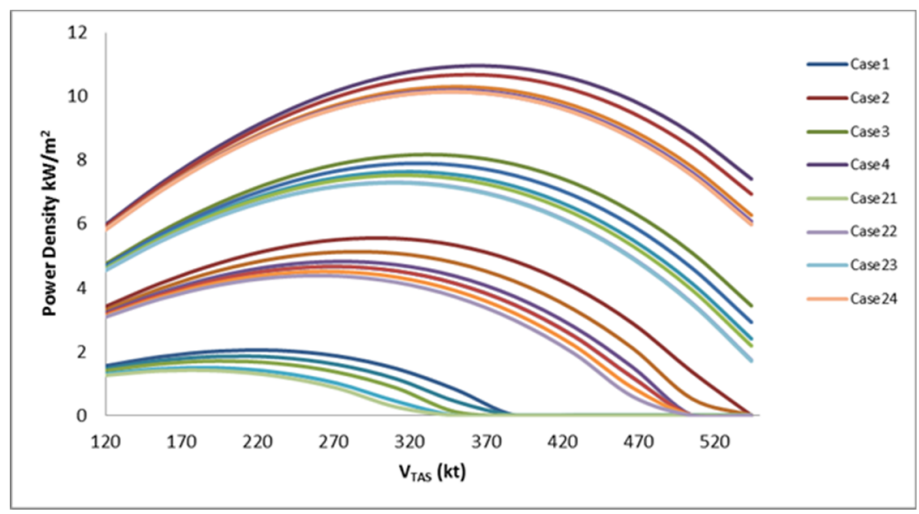

Fig. 14 Power Density for the CM Icing Envelope, MSL-22000 ft

The clouds that contain super-cooled water droplets exist at lower flight levels, and during descent and climb, the aircraft flies at low speed which lessens the effects of kinetic heating on the airframe. Thus, flight in a CM icing 
condition was further examined for 7, $000 \mathrm{ft}$ based on the temperature bands shown in Fig. 15. In all the cases, a $5^{\circ} \mathrm{C}$ skin temperature was maintained. The result indicates a minimum power requirement of about $6 \mathrm{~kW} / \mathrm{m}^{2}$ at $250 \mathrm{kts}$ assuming that ice melts at a low fixed temperature point of $0.01^{\circ} \mathrm{C}$. At a maximum air speed of $300-350 \mathrm{kt}$, a maximum power requirement of between 7 to $9 \mathrm{~kW} / \mathrm{m}^{2}$ was obtained for a maximum $5^{0} \mathrm{C}$ skin temperature.

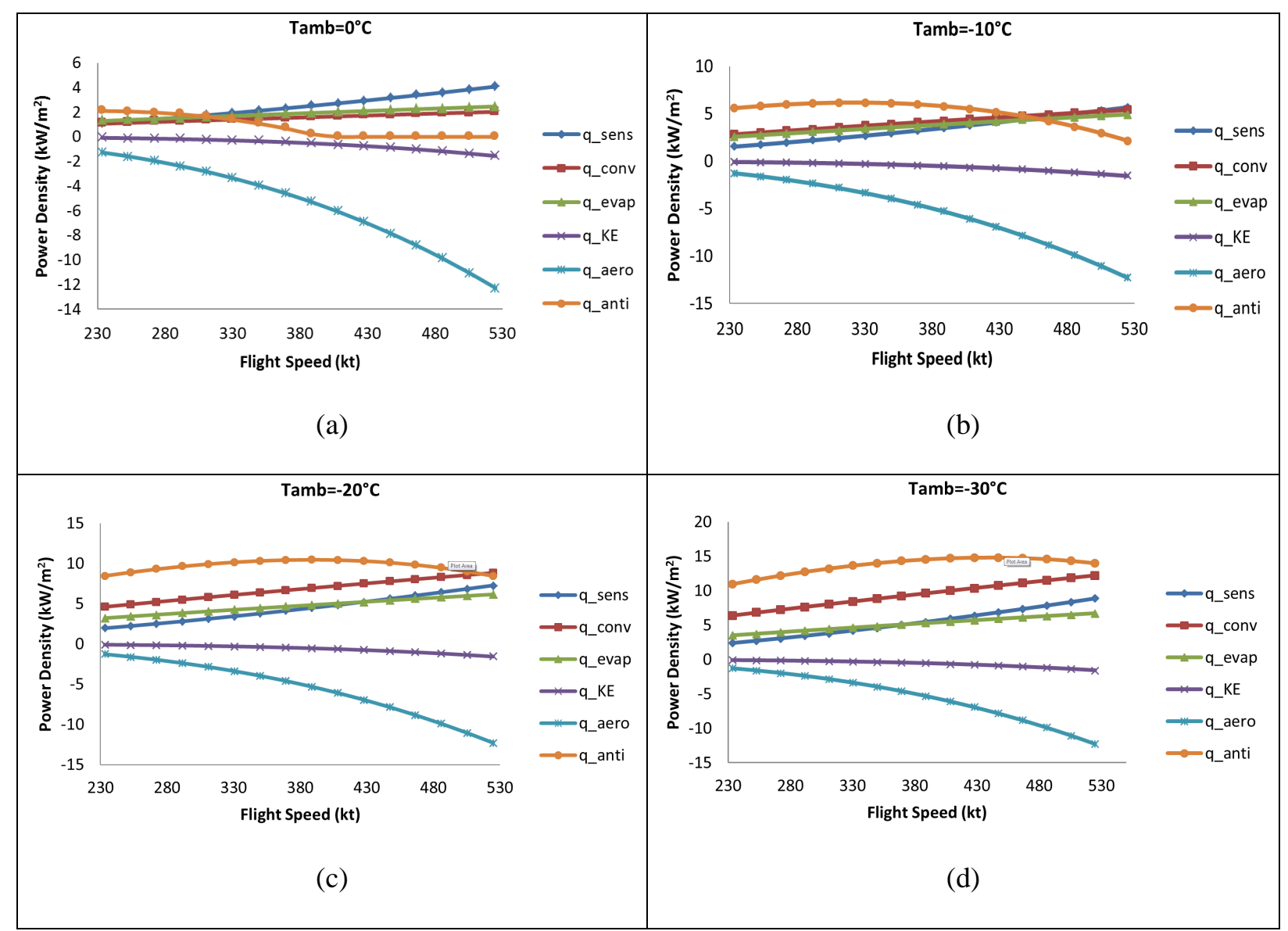

Fig. 15 Anti-icing Power Requirement at (a) $0{ }^{\circ} \mathrm{C}$, (b) $-10{ }^{\circ} \mathrm{C}$, (c) $-20{ }^{\circ} \mathrm{C}$ and (d) $-30{ }^{\circ} \mathrm{C}$

Fig. 15 (a) shows that icing does occur at $0^{\circ} \mathrm{C}$ ambient temperature but anti-icing may not be necessary except for low climb speeds. At $-10^{\circ} \mathrm{C}$ the power density is about $6 \mathrm{~kW} / \mathrm{m}^{2}$. This doubled and tripled at $-20^{\circ} \mathrm{C}$ and $-30^{\circ} \mathrm{C}$ respectively.

\subsubsection{Intermittent Maximum Icing Condition}

It can be seen in Fig. 16 that Case 3 in IM condition representing $-30^{\circ} \mathrm{C}, 1.142 \mathrm{~g} / \mathrm{m}^{3}, 15 \mu \mathrm{m}$ has the highest power requirement whereas case $23,0^{\circ} \mathrm{C}, 0.38 \mathrm{~g} / \mathrm{m}^{3}, 50 \mu \mathrm{m}$ has the lowest requirement. 


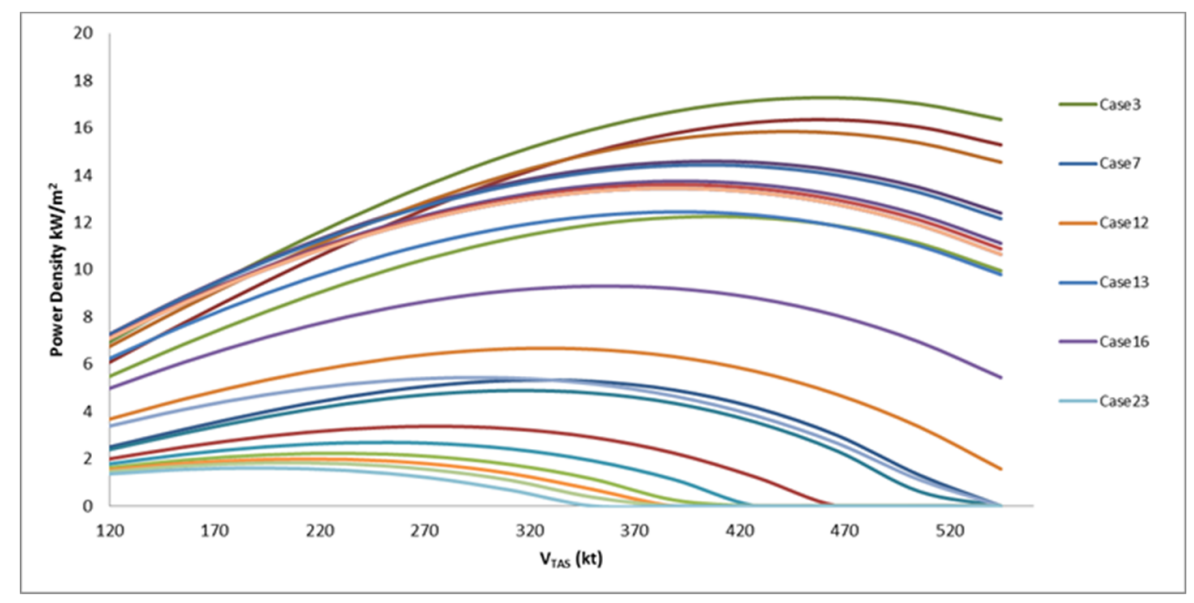

Fig. 16 Power Density for the IM Icing Envelope from 4000-22000 ft

The power densities are closely entwined, however, the difference would manifest in overall power requirement which could lead to additional system weight and off-take penalties. The upper and lower boundaries of the power demands were plotted in Fig. 17.

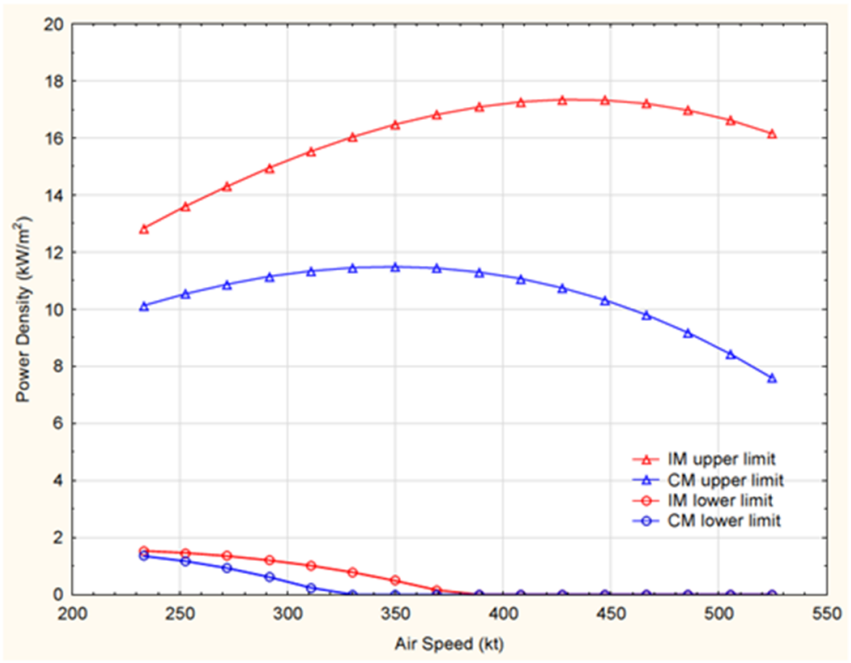

Fig. 17 Power Demand Boundaries

\subsection{Model Verification and Validation}

The ambient temperature has an important relationship with a cloud's water concentration. The lower the ambient air temperature, the lower the cloud's water concentration. The probability of encountering large amounts of super-cooled droplets reduces with decreased ambient temperature. As such, verification and validation processes were undertaken to investigate the performance of the model under a wide range of icing conditions. 


\subsubsection{Verification}

As a verification process, the sensitivity of the model to inputs variation was checked to ensure that the results were not outside expected limits. Fig. 18 shows a Gaussian distribution of the simulated result, compared to a value obtained from experimental data of the maximum anti-icing power off-take for a large aircraft wing. Based on 1000 cases generated using a pseudo-Monte Carlo simulation method, the model was accurate to within $70 \%$ and the level of sensitivity was satisfactory. The observed mean is 1.4568 , observed variance is 58.0193 , and, the upper and lower limits are -20 and 25 respectively.

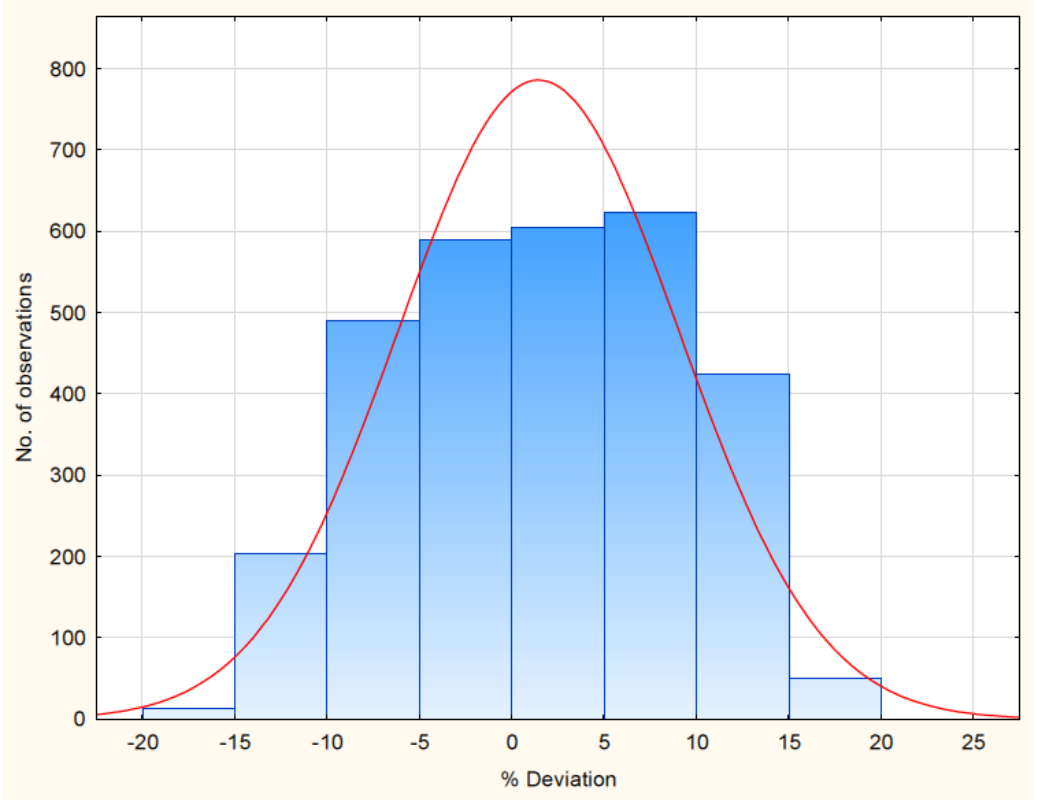

Fig. 18 Normal Distribution of Model Sensitivity to Inputs Variation

\subsubsection{Validation}

The model performance was evaluated based on an icing experimental test conducted by Al-Khalil et al [26] on the engine intake of a turbine aircraft. The same test case was run with the model developed in this work and the results obtained compared very well with the experimental result as shown in Fig. 19. 


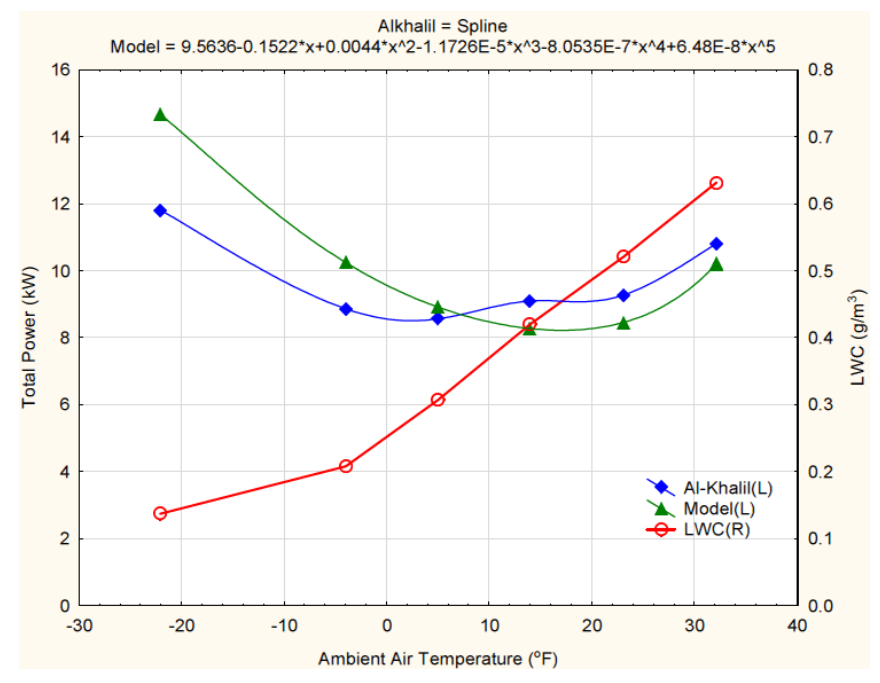

Fig. 19 IPS Model Validation with Experimental Data

The percentage deviation of the model result from the experimental result in terms of total power plotted in Fig. 20 shows less than $20 \%$ discrepancies in all the six cases. Considering certain inputs related to aircraft level parameters being estimated conservatively, the less than $20 \%$ discrepancy is acceptable. Moreover, the model will be implemented in trajectory optimisation problems where the effects of the IPS are studied. So, the quality of the model developed here is more than sufficient for the initial study.

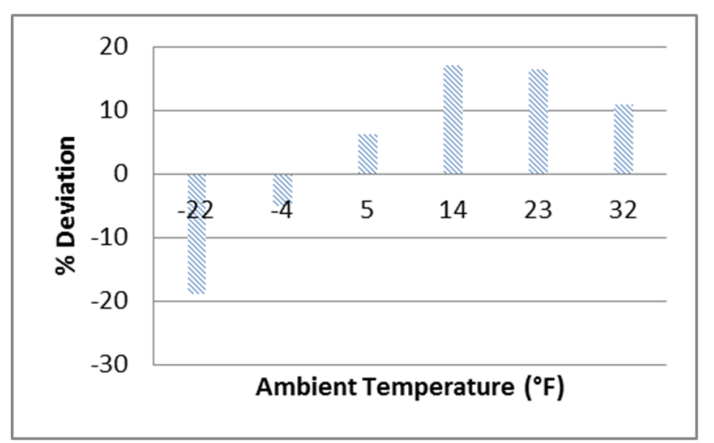

Fig. 20 Percentage Deviation from Experimental Data

Although, there is value in investigating more cases, with the satisfactory sensitivity results and the fact that the range here covers the Appendix $\mathrm{C}$ temperature range $\left(0\right.$ to $\left.-30^{\circ} \mathrm{C}\right)$ for the most severe $\mathrm{CM}$ icing conditions shows the model is of satisfactory validity for its intended purpose.

\section{Trajectory Optimisation}

Ground-based systems have served the aviation community well since inception; however as demand for air transportation services increases, they do not permit the flexibility of point-to-point operations required for the future 
ATM (Air Traffic Management) environment [27]. The International Air Transport Association (IATA) estimated that shorter PBN routes globally could cut $\mathrm{CO}_{2}$ emissions by 13 million tonnes per year [28]. Emissions are reduced by as much as $3.19 \mathrm{~kg}$ of $\mathrm{CO}_{2}$ for every $\mathrm{kg}$ of fuel saved [28]. From 2030, aircraft are expected to fly optimal trajectories that are defined in the form of three dimensional waypoints plus associated required times (4D) of overfly [29]. However, conventional approaches to trajectory optimisation do not include aircraft systems in the optimisation set up. Neglecting these effects may be inadequate, especially when one considers real aircraft operations in real weather scenarios. Hence, some selected trajectory optimisation cases were simulated to assess the impacts of including icing conditions in the optimisation schemes.

\subsection{Case Study}

There are about 650 departures from London Airport Heathrow (LHR) daily. From 2010 onwards, more than 94\% of all departures from LHR airport are tracked [30]. Thus, the selected test case is a a Standard Instrument Departure (SID) from London Airport Heathrow (EGLL/LHR) by an Amsterdam Airport Schiphol (EHAM/AMS) bound flight tracked on 14 April 2014 [31]. Fig. 21 shows a graphical projection of the departure based on the tracked data.

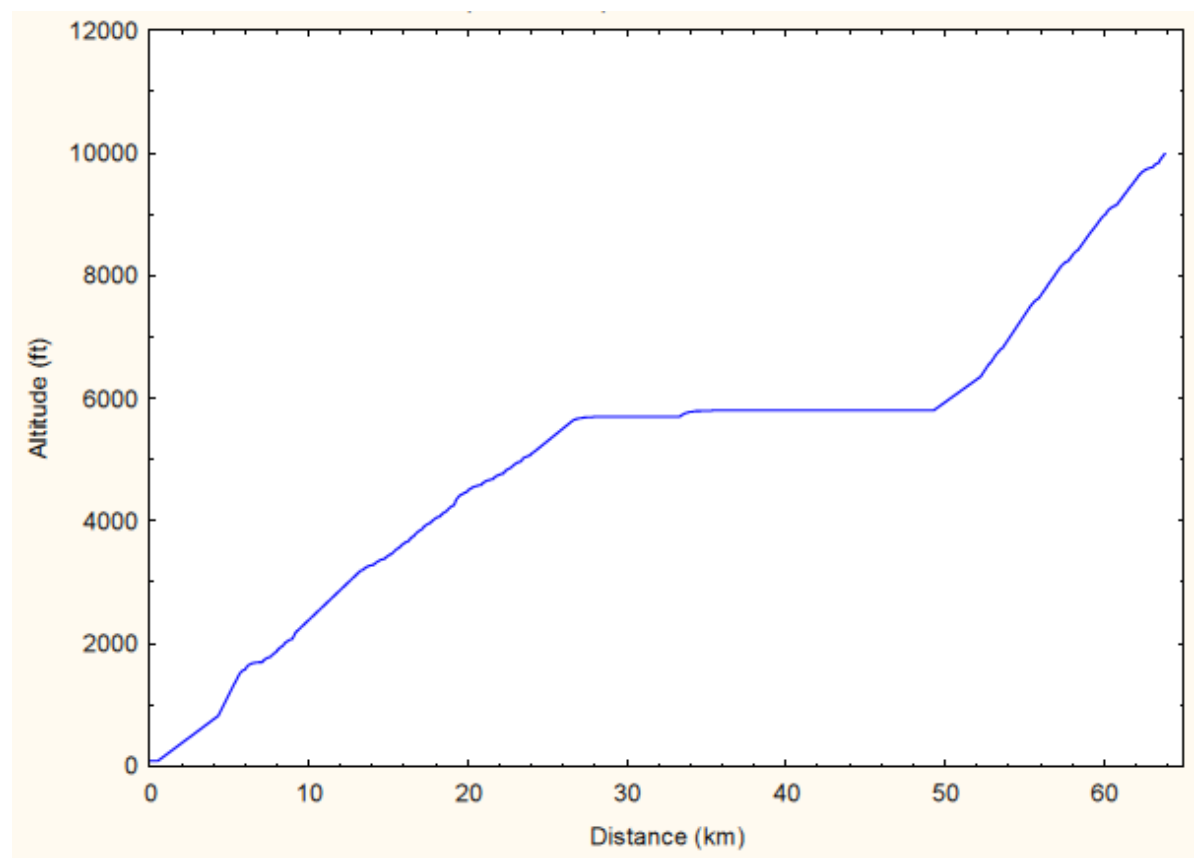

Fig. 21 A Tracked Departure from London Airport Heathrow to Amsterdam Airport Schiphol

Typically, turbofan powered transport aircraft encounter icing during climb to cruise altitude, and descent and hold. This is due the fact that the clouds that contain super-cooled water droplets exist at lower flight levels. Literature [32] 
shows that the most probable occurrence of icing is in the altitude band of 3,000-5,000 ft over the UK. At LHR airport, the ATC are responsible for routing all jet aircraft through Noise Preferential Routes (NPR) from take-off to 4,000 ft, except where there is safety concern. From 4,000 ft however, the pilot could be authorised to leave the NPR and fly a more direct heading to their destination [30]. In medium to large jet aircraft, departure phase is considered to begin with takeoff and end at FL100 [33]. To accommodate the ATC constraints, an icing scenario between 4,000 ft and 10,000 ft was built into the optimiser search domain based on Case 4 CM (see Table 5) icing conditions.

\subsection{Simulation Framework}

The model developed in this work was integrated with the GATAC (Greener Aircraft Trajectories under ATM Constraints) simulation framework. GATAC is a multi-objective optimisation framework for planning environmentally efficient trajectories. The software was co-developed by Cranfield University and University of Malta. The University of Malta developed the infrastructure code while Cranfield University developed the optimiser and the airframe systems the aircraft dynamics models required to simulate aircraft trajectories with on-board systems.

\subsection{Setup}

The trajectory optimisation problem was set up including the presence of icing conditions. The solver was run with and without considering the icing conditions in the optimisation loop. This was aimed at assessing the fuel penalties and emissions to the environment when an aircraft flies into known icing conditions. A Non-dominated Sorting Genetic Algorithm Multi-Objective (NSGAMO) optimiser was used for the simulation. The NSGAMO optimiser is capable of performing multi-objective optimisation under constraints and is based on Genetic Algorithm (GA). The conditions for the optimisation studies are: initial mass, $66,000 \mathrm{~kg}$; initial altitude, $83 \mathrm{ft}$; initial speed, $140 \mathrm{kt}$; final altitude, 10,000 ft and final speed, $310 \mathrm{kt}$. Each optimisation case consisted of 30,000 evaluations. The key settings for the optimiser included initialisation factor of 50, population of 100, and 250 generations. There are six way points for the departure which starts at $83 \mathrm{ft}$ above ground level and terminates at BPK VOR. The route settings are shown in Table 6.

Table 6. LHR-AMS Route Departure Settings

\begin{tabular}{llll}
\hline $\begin{array}{l}\text { Way } \\
\text { points }\end{array}$ & Latitude & Longitude & Term \\
\hline 1 & $512753.25 \mathrm{~N}$ & $0002854.99 \mathrm{~W}$ & WP1 \\
2 & $512752.51 \mathrm{~N}$ & $0003135.75 \mathrm{~W}$ & WP2 \\
3 & $513108.00 \mathrm{~N}$ & $0004038.00 \mathrm{~W}$ & WP3 \\
4 & $513507.13 \mathrm{~N}$ & $0003629.69 \mathrm{~W}$ & WP4
\end{tabular}




\begin{tabular}{llll}
5 & $513723.00 \mathrm{~N}$ & $0003107.00 \mathrm{~W}$ & WP5 \\
6 & $514459.00 \mathrm{~N}$ & $0000624.00 \mathrm{~W}$ & BPK \\
\hline
\end{tabular}

\subsection{Preliminary Results and Discussion}

\subsubsection{Impacts of the Different Optimisation Approaches on Aircarft Performance}

Fig. 22 shows the Pareto fronts for the conventional and the icing in the loop approaches after optimisation of the departure. Conventional approach here refers to the use of aircraft dynamics and engine models, and any other aircraft system aside AI system; whereas, icing in the loop means building in icing conditions in the optimisation setup. It can be noted in Fig. 22 that flying icing optimised trajectories when operating in known icing conditions, gave a $2.1 \%$ fuel savings over flying conventionally optimised trajectories. The two solutions are quite close with respect to minimum time. This is expected as the case is a short flight segment.

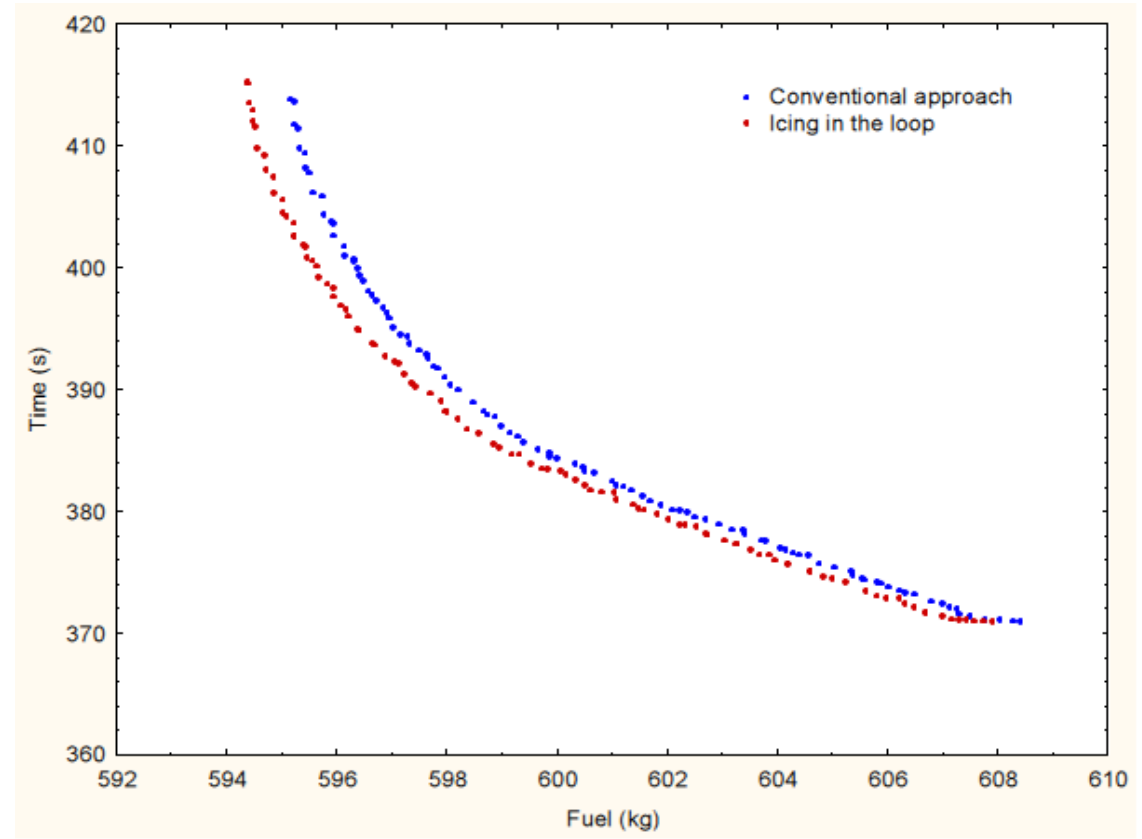

Fig. 22 Pareto Front of Fuel vs Time Optimisation

The difference for a single flight segment is small and power off-take due to icing is small. However, considering that 83,000 departures [34] that take place globally every day and the appreciable number of these that encounter icing conditions, the combined effect of the global fleet is significant. Similarly, considering flights in non-standard icing condition for example of the extent of 200nm; the relevance of this approach to ACARE objectives is apparent. The associated trajectories in the two approaches are shown in Fig. 23. 


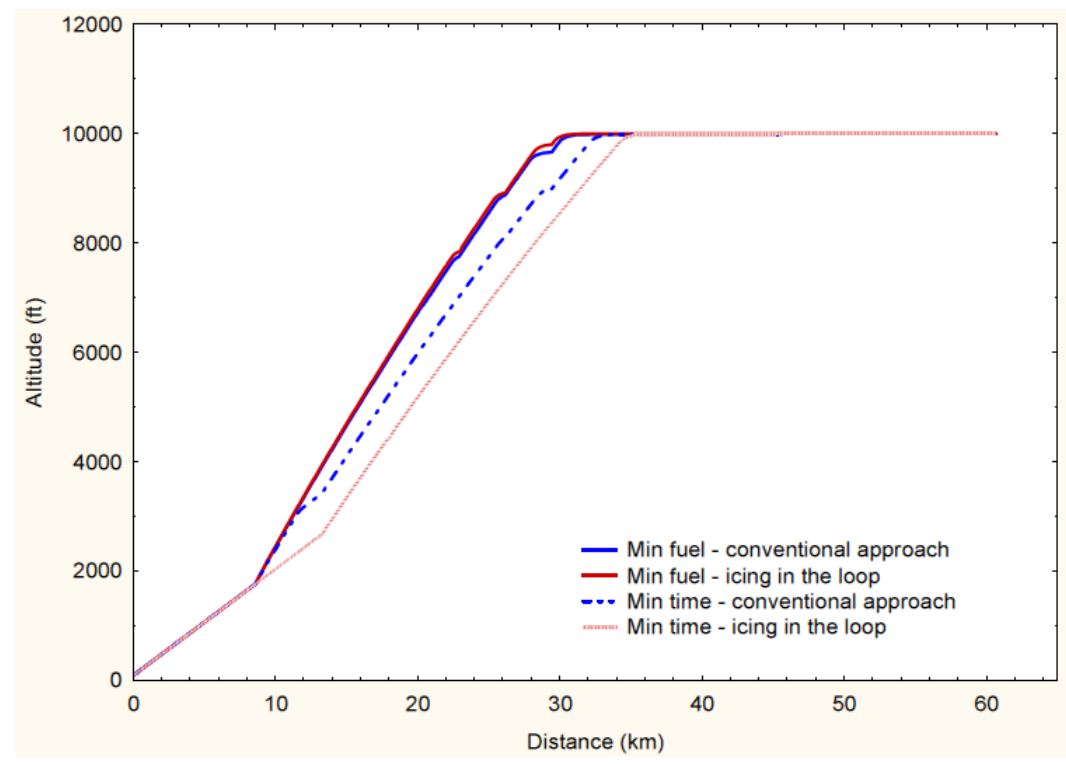

Fig. 23 Flight Route Comparison

When icing was included in the optimisation loop, the aircraft flew at a slightly higher altitude than in the conventional approach. This is expected as the optimiser finds points of low fuel consumption at higher altitudes than lower altitudes. Hence, the different projections of the two-approach based trajectories indicates that, there is a benefit in flying the aircraft in a different way in the presence of icing conditions. Aircraft trajectory is defined in terms of altitude and air speed. Air speed has a significant effect on AI system energy consumption. Faster aircraft are likely to consume less energy than slower ones due to kinetic and aerodynamic heating. As can be seen in Fig. 24, including the AI algorithm in the set up made the aircraft to fly at higher CAS than in the conventional approach. Because of the higher CAS in the enhanced approach, the kinetic heating is more; hence, less AI power is required. 


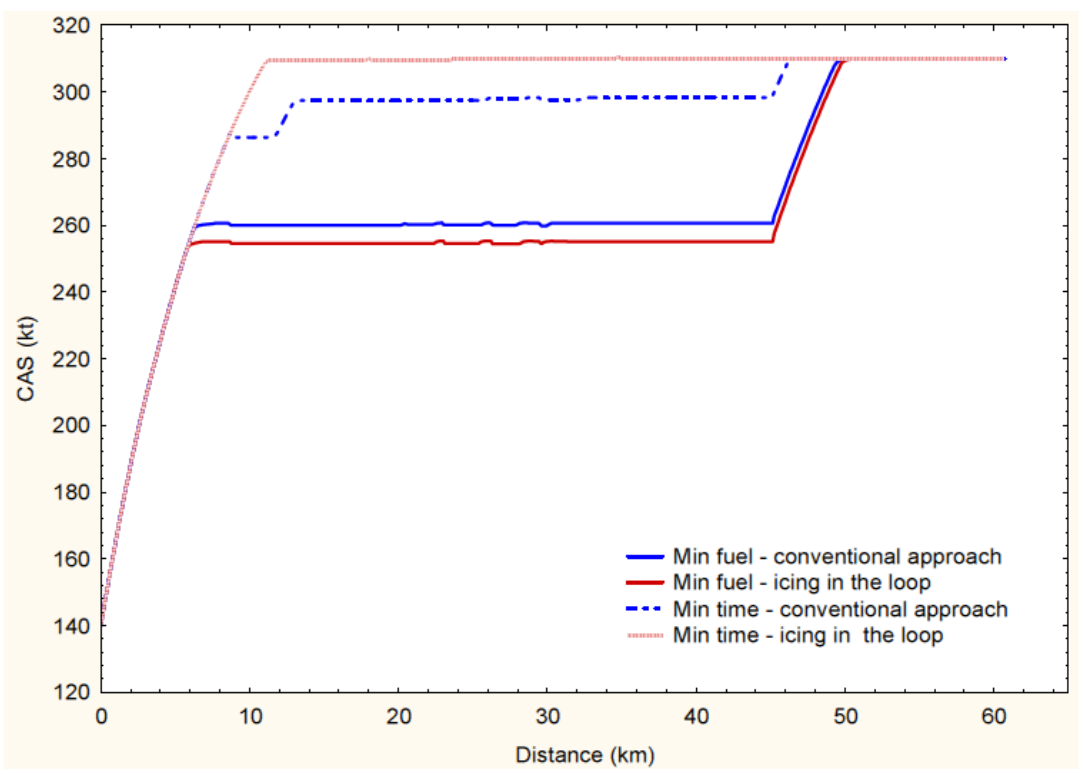

Fig. 24 Aircraft CAS Comparison

Fuel and time were the objectives of the optimisation. However, the discussion below focused on the fuel burn as the aim of the discussion is to evaluate the two optimisation approaches. Furthermore, fuel efficiency is a top priority next to safety to aircraft operators. It is the highest cost in aircraft ownership, representing $30.5 \%$ of the total operating cost [35]. The fuel flow is a function of the speed, altitude, throttle setting and power off take. It can be observed in Fig. 25 that the reduction in AI power requirement associated with the enhanced approach has helped to reduce the fuel flow.

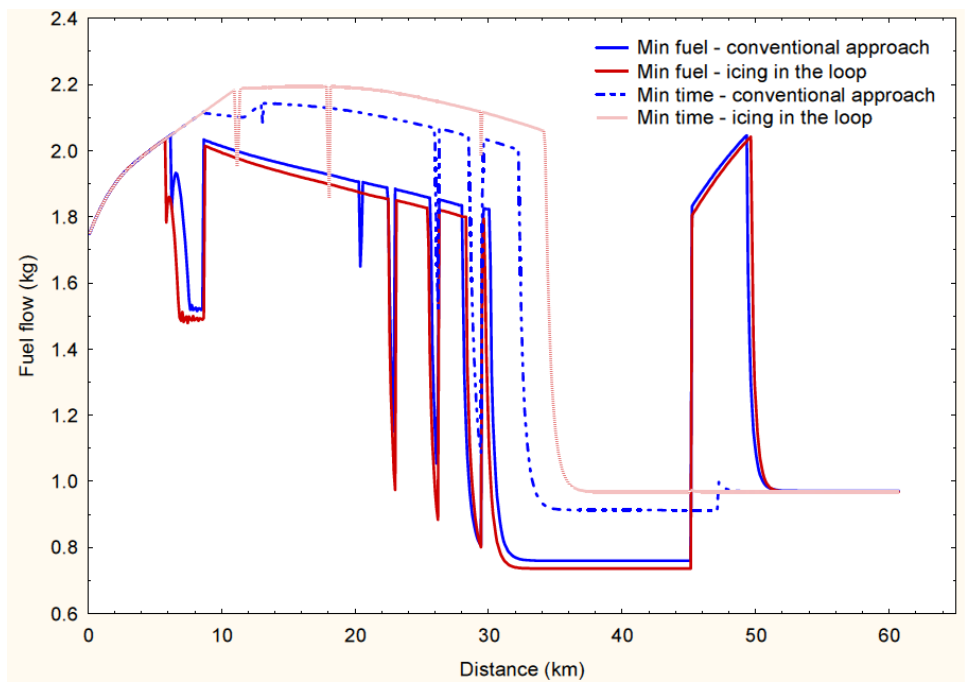

Fig. 25 Fuel Flow Comparison

Fuel burn can be measured from the reduction in the initial aircraft mass. As can be seen from Fig. 26, more fuel was burnt in the conventional approach than in the enhanced approached. 


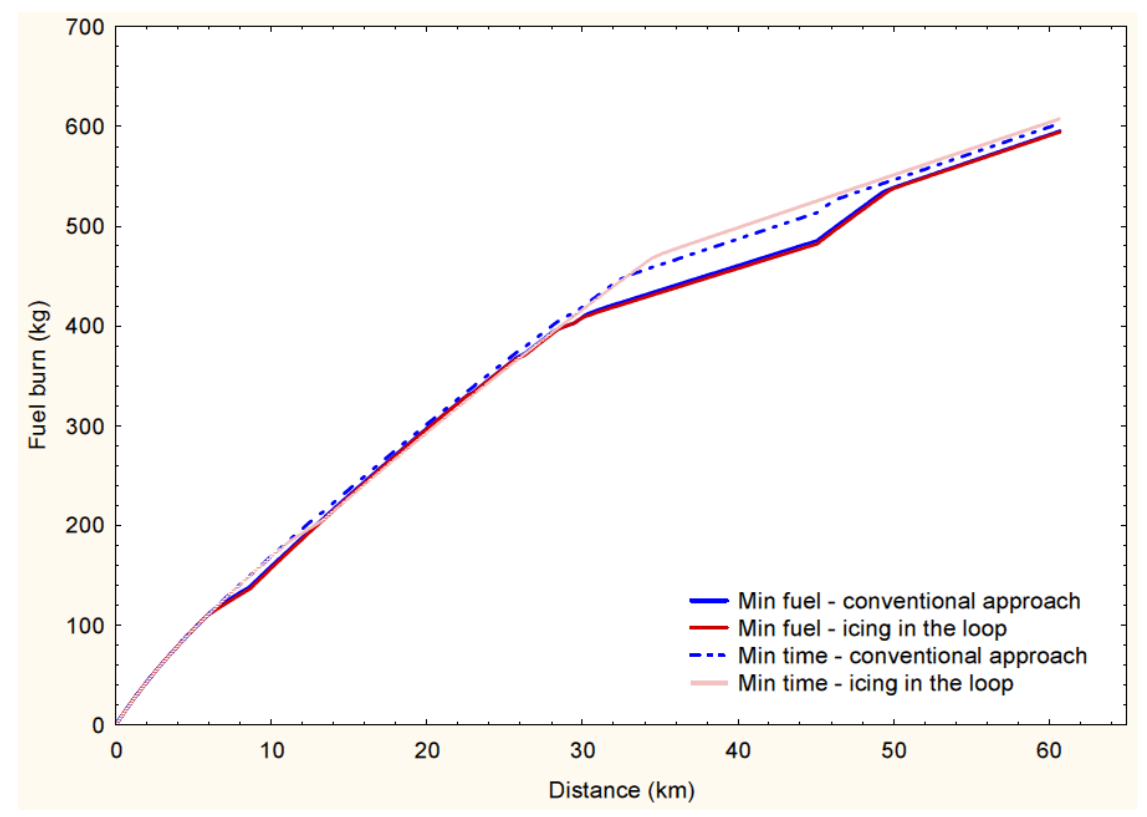

Fig. 26 Fuel Burn Comparison

\subsubsection{Environmental Gains}

The production of the greenhouse gas is directly correlated with fuel consumption [36]. Hence, savings in fuel translates to a direct savings on greenhouse gas (GHG) emissions. Fig. 27 and Fig. 28 show the difference in total $\mathrm{CO}_{2}$ and $\mathrm{NO}_{\mathrm{x}}$ emissions respectively for the enhanced approach and the conventional approach to trajectory optimisation in the presence of icing conditions. As can be seen, there is a GHG saving in the enhanced approach compared to the conventional approach.

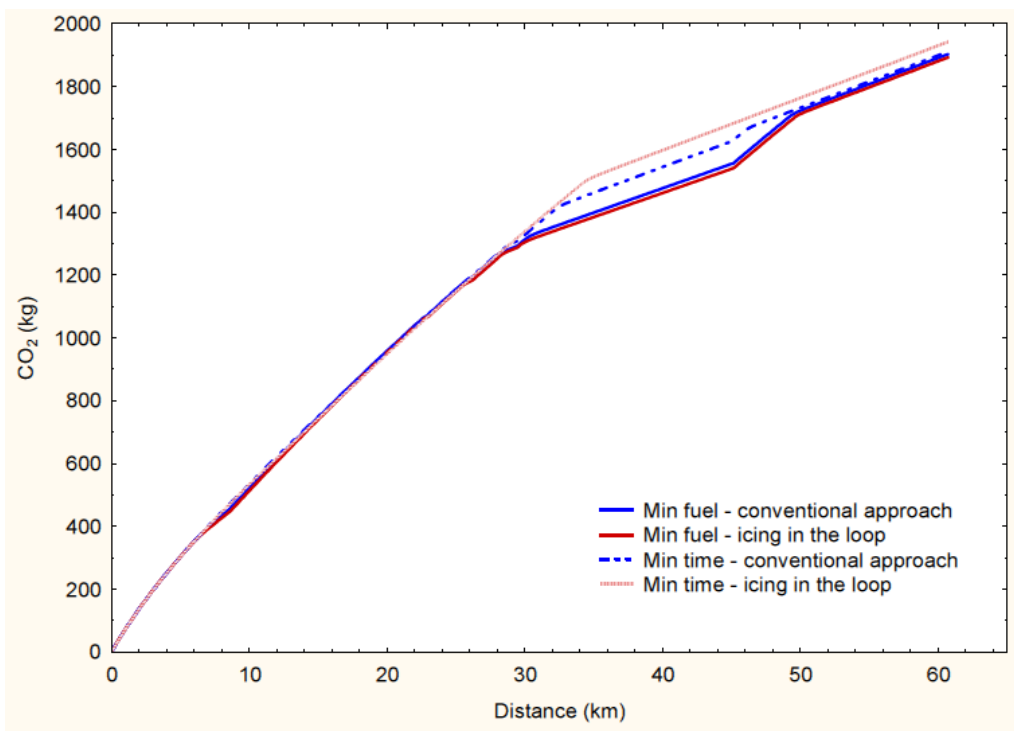

Fig. 27 Total $\mathrm{CO}_{2}$ Emission Comparison 


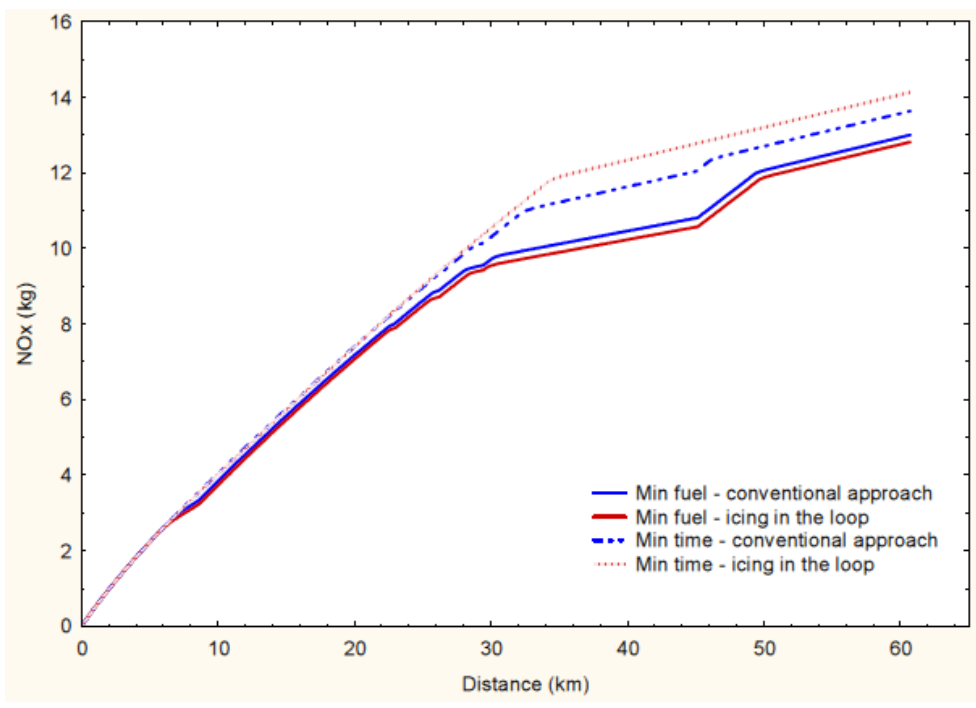

Fig. 28 Total NOx Emission Comparison

\section{Conclusions and Future Work}

An enhanced aircraft anti-icing model was developed based on Messinger mass and energy balance method for aircraft icing simulation. The aim of the work is to incorporate major aircraft systems into aircraft trajectory optimisation in order to demonstrate the environmental gains that can be achieved if such optimised flight profiles are flown. This would enable the development of a consistent and cohesive strategy of managing inflight icing in a future ATM (Air Traffic Management) environment that enables efficient flight planning. The reconfigurable version of the model developed in this work was successfully integrated with a trajectory optimisation framework for independent assessment of fuel penalty due to icing and investigation of pollutant emissions reduction through a mission profile optimisation. The solution obtained here are for one icing case. Simulating more cases within the Appendix C icing envelope could facilitate better understanding of the effects of icing parameters on aircraft trajectories when considered in optimisation schemes. However, it can be concluded based on the above analysis that icing in the loop trajectories are more efficient than conventionally optimised trajectories when flying in known icing conditions, assuming no ATC constraints are engaged.

The future work proposes an intelligent, controllable ice protection system for aircraft fitted with future air navigation systems. The research aims to investigate ways to operate aircraft at low power levels through changes in aircraft operation strategy that take into account optimised flight routings in the presence of icing conditions. The IPS model in the present work would be used for evaluating the total system burden within an algorithm for intelligent operation so 
that potential savings associated with routing could be investigated. Fig. 29 shows a schematic diagram of the approach to the controllable anti-icing system in a future ATM environment.

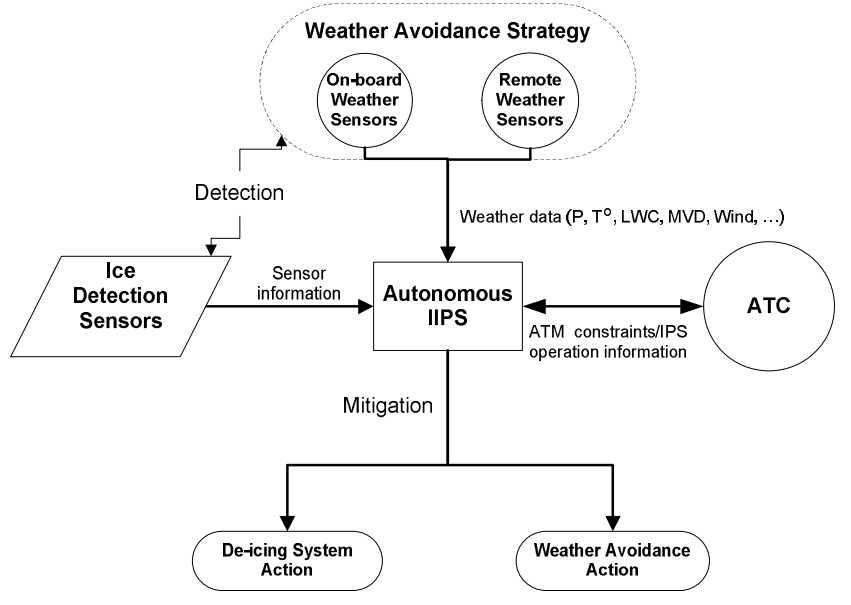

Fig. 29 A Systematic Approach to Controllable Aircraft Anti-icing in a Future ATM System

\section{Acknowledgements}

The authors acknowledge the support of Clean Sky in the development of GATAC trajectory optimisation software.

The authors also acknowledge the support of Dr. David Hammond, Ravinka Seresinhe and Daniele Qualia, Cranfield University, in this work for their respective advice on aircraft icing and systems modelling.

\section{Nomenclature}

ACARE Advisory Council for Aeronautics Research in

AI Anti-icing

ATC Air Traffic Control

ATM Air Traffic Management

$\mathrm{c}, \mathrm{C}_{\mathrm{p}} \quad$ Specific heat $(\mathrm{J} / \mathrm{kg} . \mathrm{K})$

$\mathrm{d} \quad$ Ice thickness (m)

$\mathrm{d}_{\mathrm{med}} \quad$ Median droplets size $(\mu \mathrm{m})$

DRR Droplets range ratio (dimensionless)

e Saturation pressure $(\mathrm{hPa})$

$\mathrm{E}_{\mathrm{m}} \quad$ Overall collection efficiency (\%)

GHG Greenhouse gas

ho Local heat transfer coefficient (W/K.m2)

$\mathrm{h}_{\text {proj }} \quad$ Aerofoil projected height $(\mathrm{m})$

hs $\quad$ Skin Heat transfer coefficient (W/K.m2)

$\mathrm{i}, \mathrm{h} \quad$ Subscripts $\mathrm{i}$ and $\mathrm{h}$ refer to ice and heater

IIPS Intelligent ice protection system

IPS Ice Protection System 


\begin{tabular}{|c|c|}
\hline $\mathrm{K}$ & Inertia parameter (dimensionless) \\
\hline Le & Latent heat for water evaporation $(\mathrm{kJ} / \mathrm{kg})$ \\
\hline $\mathrm{LE}$ & Leading Edge \\
\hline LWC & Clouds liquid water content (g/m3) \\
\hline $\mathrm{mi}$ & Icing rate $(\mathrm{kg} / \mathrm{s})$ \\
\hline MVD & Medium Volumetric Diameter $(\mu \mathrm{m})$ \\
\hline mw & Water mass flow rate $(\mathrm{kg} / \mathrm{s})$ \\
\hline NPR & Noise Preferential Routes \\
\hline OAT & Outside Air Temperature (K) \\
\hline $\mathrm{P}$ & Pressure $(\mathrm{hPa})$ \\
\hline $\mathrm{R}_{\mathrm{c}}$ & Boundary recovery factor (dimensionless) \\
\hline $\operatorname{Re}_{\mathrm{d}}$ & Droplets Reynolds number (dimensionless) \\
\hline $\mathrm{Rh}$ & Relative humidity (\%) \\
\hline $\mathrm{s}, \mathrm{L}$ & Subscripts s and L refer to solid and liquid states \\
\hline S0 & Reference protected area (m2) \\
\hline $\mathrm{T}$ & Ambient temperature $\left({ }^{\circ} \mathrm{C}\right)$ \\
\hline ticing & Time in icing encounter $(\mathrm{s})$ \\
\hline $\mathrm{T}_{\mathrm{m}}$ & Melting temperature $\left({ }^{\circ} \mathrm{C}\right)$ \\
\hline $\mathrm{T}_{\mathrm{sk}}$ & Skin temperature $\left({ }^{\circ} \mathrm{C}\right)$ \\
\hline $\mathrm{V}_{\mathrm{CAS}}$ & Calibrated air speed (kt) \\
\hline $\mathrm{V}_{\mathrm{TAS}}$ & True air speed $(\mathrm{kt})$ \\
\hline$x$ & Characteristic length (m) \\
\hline$\alpha$ & Angle of attach $\left(^{\circ}\right)$ \\
\hline$\lambda, \mathrm{k}_{0}$ & Thermal conductivity of air (W/m.K) \\
\hline$\mu$ & Absolute viscosity of air (kg/s.m) \\
\hline$\rho$ & Density $\left(\mathrm{kg} / \mathrm{m}^{3}\right)$ \\
\hline$\Delta L_{f_{\text {ice }}}$ & Latent heat of fusion of ice $(\mathrm{kJ} / \mathrm{kg})$ \\
\hline$\Delta T$ & Temperature difference $\left({ }^{\circ} \mathrm{C}\right)$ \\
\hline
\end{tabular}

\section{References}

[1] SESAR (2012), SESAR Releases: Advancing ATM Modernisation, available at: http://www.sesarju.eu/news-press/news/sesar-releases-advancing-atm-modernisation-1055 (accessed 03/26).

[2] Advisory Council for Aeronautics Research in Europe (2008), Addendum to the Strategic Research Agenda, 2008. Brussels, ACARE.

[3] Wright, W. B. (2002), User Manual for the NASA Glenn Ice Accretion Code: LEWICE 2.2.2 Final Report, NASA/CR-2002-211793, NASA, Washington DC.

[4] Gent, R. (1990), TRAJICE2: A Combined Water Droplet Trajectory and Ice Accretion Prediction Program for Aerofoils, RAE TR 90054, Royal Aircraft Establishment, Farnborough.

[5] Henry, R. (1992), Development of an Electrothermal De-icing/Anti-Icing Model, ONERA TAP 92005, ONERA, Chatillon Cedx, France.

[6] Aero Tex (2012), Aircraft Icing Analysis Codes, available at: http://www.aerotex.co.uk/analysis_codes/analysis_codes.htm (accessed Apr/24).

[7] BAE Systems (2011), 3D Ice Prediction Tool - ICECREMO2, available at: http://www.baesystems.com/ProductsServices/ss_tes_atc_icecremo.html (accessed 01/30). 
[8] Morency, F., Brahimi, M.T., Tezok, F., Paraschivoiu, I. (1998), Hot Air Anti-icing System Modelization in the Ice Prediction Code CANICE, AIAA 98-0192, AIAA, Washington.

[9] Newmerical Technologies Int. (2009), FENSAP-ICE Inflight Icing Simulation System, available at: http://www.newmerical.com/index.php/products/cht3d-cfd-software/ (accessed 01/09).

[10] Messinger, B. L. (1953), "Equilibrium Temperature of an Unheated Icing Surface as a Function of Air Speed", Journal of The Aeronautical Sciences, vol. 20, no. 1, pp. 29-42.

[11] Gent, R. W., Dart, N. P. and Cansdale, J. T. (2000), "Aircraft Icing", The Royal Society, , no. 358, pp. 2873-2911.

[12] Thomas, S. K., Cassani, R. P. and MacAthur, C. D. (1996), "Aircraft Anti-Icing and De-Icing Techniques and Modeling", Journal of Aircraft, vol. 33, no. 5, pp. 841-854.

[13] Bu, X., Lin, G., Yu, J., Shen, X. and Hou, P. (2013), "Numerical Analysis of a Swipt Wing Hot Air Ice Protection System", Proceedings of the Institution of Mechanical Engineers, Part G: Journal of Aerospace Engineering, .

[14] Bu, X., Lin, G., Yu , J., Yang, S. and Song, X. (2013), "Numerical Simulation of an Airfoil Electrothermal Anti-icing System", Proceed of the Institute of Mechanical Engineers, Part G: Journal of Aerospace Engineering, , no. 227, pp. 1608-1622.

[15] Miller, D., Bond, T., Sheldon, D., Wright, W., Langhals, T., Al-Khalil, K. and Broughton, H. (1997), Validation of the NASA Thermal Ice Protection Computer Codes , Part 1-Program Overview, AIAA-970049, NASA, Cleveland, Ohio.

[16] Krumpak, D. (2010), Ice Protection System for a New Generation Aircraft (unpublished MSc thesis), Cranfield University, Cranfield.

[17] Meier, O. and Scholz, D. (2010), A Handbook Method for the Estimation of Power Requirements for Electrical De-icing Systemms, 161191, Hamburg University of Applied Sciences, Hamburg, Germany.

[18] Jeck, R. K. (2002), Icing Design Envelopes (14 CFR Parts 25 and 29, Appendix) Converted to a Distance-Based Format, DOT/FAA/AR-00/30, FAA, Washington.

[19] FAA (2007), Pilot Guide: Flight in Icing Conditions, 91-74A, FAA.

[20] Bowden, D. T., Gensemer, A. E. and Skeen, C. A. (1964), Engineering Summary of Airframe Icing Technical Data, FAA ADS-4, FAA, Washington, D.C.

[21] SAE Aerospace (1989), Ice, Rain, Fog, and Frost Protection, AIR1168/4, Society of Automative Engineers, Inc, PA.

[22] Krammer, P. and Scholz, D. (2009), Estimation of Electrical Power for Deicing Systems, , Hamburg University of Applied Sciences, Hamburg.

[23] Shinkafi, A. and Lawson, C. (2013), "Evaluating Inflight Ice Protection Methods for Applications on Next Generation Aircraft", Journal of Aerospace Engineering and Technology, , no. 2231-038X.

[24] Cao, Y. and Zhang, Q. (2008), "Numerical Simulation of Rime Ice Accretions on an Aerofil Using an Eulerian Method", The Aeronautical Journal, , no. 3230, pp. 243-249.

[25] NOAA (2014), Aircraft Icing, available at: http://www.crh.noaa.gov/images/lmk/Brian\%20S/LMK_Icing_Show.pdf (accessed 10/23).

[26] Al-Khalil, A., Hitzigrath, R., Philippi, O. and Bidwell, C. (2000), "Icing Analysis and Test of a Business Jet Engine Inlet Duct", 38th Aerospace Sciences Meeting \& Exhibit, 10-13 January 2000, .

[27] Schumann, U. (2012), "Volcanic, Weather and Climate Effects on Air Transport", 28th International Congress of the Aeronautical Sciences, 23-28 September, 2012, Brisbane, Optimage Ltd, Brisbane, Australia, .

[28] ICAO (2009), Performance Based Navigation, Document 9613, ICAO.

[29] SESAR (2012), The Roadmap for Sustatinable Air Traffic Management: European ATM Master Plan, Edition 2, EU.

[30] Heathrow Airport Limited (2014), Heathrow Official Airport Website: Departures, available at: http://www.heathrowairport.com/static/Heathrow_Noise/Downloads/PDF/Departures11.pdf （accessed 06/09).

[31] FlightAware (2014), Live Flight Tracking, available at: 

May/23).

[32] Roach, W. T., Forrestor, D. A., Crewe, M. E. and Watt, K. F. (1984), An Icing Climatology for Helicopters, Meteorological Office, Bracknell.

[33] Yutko, B. M. and Hansmann, R. J. (2011), Approaches to Representing Aircraft Fuel Efficiency Performance for the Purpose of a Commercial Aircraft Certification Standard, ICAT-2011-05, MIT International Center for Air Transportation (ICAT), Cambridge, USA.

[34] ICAO (2014), 2013 ICAO Air Transport Results Confirm Ruburst Passenger Demand, Sluggish Cargo Market, available at: http://www.icao.int/Newsroom/News\%20Doc\%202013/COM.43.13.ECON-RESULTS.Final-2.en.pdf (accessed Jan/15).

[35] Wesley, S. (2012), "Saving Fuel: It's a Team Sport", IATA 8th Maintenance Cost Conference - MCC 2012 Atlanta, October 17 - 19, Airbus, Atlanta, .

[36] Ryerson, M. S., Hansen, M. and Bonn, J. (2011), "Fuel Consumption and Operational Performance", Ninth USA/Europe Air Traffic Management Research and Development Seminar (ATM2011) . 


\section{Development of a tool to study aircraft trajectory optimisation in the presence of icing conditions}

Shinkafi, Ahmed

SAGE Publications (UK and US)

Shinkafi A \& Lawson C., Development of a tool to study aircraft trajectory optimisation in the presence of icing conditions, Proceedings of the Institution of Mechanical Engineers, Part G: Journal of Aerospace Engineering, Volume 229, Issue 8, 2015, pp.1464-1484.

https://doi.org/10.1177/0954410014553489

Downloaded from Cranfield Library Services E-Repository 